\title{
The plastic nervous system of Nemertodermatida
}

\author{
Olga I. Raikova ${ }^{1,2}$ - Inga Meyer-Wachsmuth ${ }^{3,4,5}$ • Ulf Jondelius ${ }^{3,4}$
}

Received: 7 July 2015 / Accepted: 11 November 2015

(C) Gesellschaft für Biologische Systematik 2015

\begin{abstract}
Nemertodermatida are microscopic marine worms likely to be the sister group to acoels, forming with them the earliest extant branch of bilaterian animals, although their phylogenetic position is debated. The nervous system of Flagellophora cf. apelti, Sterreria spp. and Nemertoderma cf. westbladi has been investigated by immunohistochemistry and confocal microscopy using anti-tubulin, anti-5-HT and anti-FMRFamide antibodies. The nervous system of $F$. cf. apelti is composed of a large neuropile and a loose brain at the level of the statocysts with several nerve fibres surrounding them and innervating the broom organ. Sterreria spp. shows a commissural-like brain and several neurite bundles going frontad and caudad from this. At the level of the statocysts there is also a thicker aggregation of immunoreactive fibres. The nervous system of $N$. cf. westbladi consists of a nerve ring lying outside the body wall musculature at the level
\end{abstract}

Olga I. Raikova and Inga Meyer-Wachsmuth contributed equally to this work.

Olga I. Raikova

oraikova@gmail.com

1 Zoological Institute of the Russian Academy of Sciences, Universitetskaya emb., 1, 199034 St.-Petersburg, Russia

2 Saint-Petersburg State University, Faculty of Biology, Chair of Invertebrate Zoology, Universitetskaya emb., 7/9, 199034 St.-Petersburg, Russia

3 Department of Zoology, Swedish Museum of Natural History, Box 50007, 10405 Stockholm, Sweden

4 Department of Zoology, Stockholm University, 10405 Stockholm, Sweden

5 Present address: Institute of Parasitology, Biology Centre of the Czech Academy of Sciences, Branišovská 31, 37005 České Budějovice, Czech Republic of the statocyst and a pair of ventro-lateral neurite bundles, from which extend thinner fibres innervating the ventral side of the animal. Numerous bottle-shaped glands were observed, innervated by fibres starting both from the brain and the neurite bundles. The nervous system of the nemertodermatids studied to date displays no common pattern; instead, there is considerable plasticity in the general morphology of the nervous system. In addition, the musculature of Sterreria spp. has been studied by phalloidin staining. It shows diagonal muscles in the anterior quarter of the body and a simple orthogonal grid in the posterior three quarters, being simpler than that of the other nemertodermatids. High-resolution differential interference contrast microscopy permitted to better visualize some morphological characters of the species studied, such as statocysts, sperm and glands and, in combination with anti-tubulin staining, describe in detail the broom organ in $F$. cf. apelti. Finally, we note an apparent absence of innervation of the gut in Nemertodermatida similar to the condition in Xenoturbella.

Keywords Flagellophora $\cdot$ Sterreria $\cdot$ Nemertoderma . Nemertodermatida $\cdot$ Nervous system .

Immunohistochemistry $\cdot$ Musculature $\cdot$ Statocyst $\cdot$ Broom organ $\cdot$ Glands $\cdot$ Sperm

\section{Introduction}

Nemertodermatida are marine microscopic worms that have recently attracted attention due to controversies regarding their phylogenetic position and their ensuing importance for our understanding of the evolution of bilaterian complexity. Nemertodermatida are often considered the sister group of the somewhat better known group Acoela forming with them the taxon Acoelomorpha (Ehlers 1985), although this phylogenetic hypothesis has been questioned based on molecular 
phylogenetics (Wallberg et al. 2007; Paps et al. 2009). However, the most recent phylogenomic studies do support the Acoelomorpha (Hejnol et al. 2009; Philippe et al. 2011). The overall position of nemertodermatids (with or without Acoela as a sister group) on the metazoan tree of life is also disputed. Initially, they were classified within Platyhelminthes (Steinböck 1930; 1932; Westblad 1937; Karling 1940; Ehlers 1985), but molecular phylogenetics and phylogenomics have consistently rejected this relationship, placing them as an early bilaterian branch diverging before the evolution of Nephrozoa, either separate from Acoela (Jondelius et al. 2002; Wallberg et al. 2007; Paps et al. 2009) or as part of Acoelomorpha (Hejnol et al. 2009, Srivastava et al. 2014). A competing phylogenomic hypothesis placed Acoelomorpha nested within Deuterostomia (Philippe et al. 2011). In the analyses of both Hejnol et al. (2009) and Philippe et al. (2011), Acoelomorpha were recovered as sister group to the enigmatic Xenoturbella and the latter coined this new clade Xenacoelomorpha. Xenoturbella is a meiobenthic worm with a similarly unstable phylogenetic position and a simple intra-epidermal nerve net without brain.

Each of the two mutually incompatible hypothesized phylogenetic positions of Nemertodermatida (early branching bilaterian lineage or a drastically reduced deuterostome) warrants thorough examination of their morphology. In the first case, data on nemertodermatid morphology will facilitate inferences about the morphology of the last common bilaterian ancestor and the gradual evolution of morphological complexity within Bilateria. The alternative deuterostome hypothesis entails a number of losses of morphological traits, e.g. body cavity, anus, excretory organs as well as a reorganization of the nervous system (NS), and the first step towards understanding the drastic evolutionary reversal implied by this hypothesis would be to acquire detailed knowledge of nemertodermatid morphology.

The NS of Acoela, the likely sister group of Nemertodermatida, has been investigated in several groups and is a spectacular example of NS plasticity. Even closely related species display noticeably different NS organization: for instance, Faerlea glomerata Westblad, 1945 has a superficial weak barrel-shaped 5-HT immunoreactive (IR) brain (we follow the terminology suggested by Richter et al. (2010)), while its close relative Avagina incola Leiper, 1902 displays a deep concentrated bridgeshaped brain (Reuter et al. 2001b). The acoel NS variability was further demonstrated by the examination of seven representatives of Childiidae, a group of Acoela for which there is strongly corroborated phylogenetic hypothesis (Raikova et al. 2004b). The study demonstrated that the brains in childiid species, although diverse in detail, still follow the same general pattern, and the complexity of this pattern progressively increases in accordance with the phylogenetic tree. The conclusion from these observations was that there was a lot of parallel evolution of NS characters in Acoela.

Of the currently known 18 nominal species (MeyerWachsmuth et al. 2014), only two, Nemertoderma westbladi Steinböck, 1938 and Meara stichopi Westblad, 1949b, are consistently available for collection in relatively high numbers at known localities. We have previously studied 5-HT and RFamide immunoreactivity in these two species. In $N$. westbladi, a basiepidermal symmetrical ring-shaped brain composed of 5-HT and GYIRF IR fibres as well as two ventro-lateral neurite bundles were revealed (Raikova et al. 2000a; 2004a). In M. stichopi, no brain was detected; only two loose dorso-lateral longitudinal bundles of nerve fibres and an infraepidermal nerve net were observed (Raikova et al. 2000a). Recently, Børve and Hejnol (2014) have demonstrated that the NS of $M$. stichopi is entirely basiepidermal and confirmed the absence of a brain. Thus, the NS of Nemertoderma and Meara resembles the basiepidermal nerve net proposed to be present in the bilaterian ancestor (Gröger and Schmid 2001; Raikova et al. 2004a; Perea-Atienza et al. 2015).

The present study provides a further insight into the nemertodermatid NS by increasing the taxonomic sampling and the markers used. We have investigated the NS patterns in less common species of Nemertodermatida, Flagellophora cf. apelti Faubel and Dörjes, 1978 (Ascopariidae) and Sterreria spp. (Nemertodermatidae), using anti-FMRFamide, anti-5-HT and anti-tubulin antibodies. The most striking feature of $F$. cf. apelti is a broom organ, a set of long bristles with adhesive tips that can be protruded through an anterior pore and spread out as a fan. The species of Sterreria are longer and more slender than the other nemertodermatids for which the NS has been studied. We have also obtained additional data on $N$. cf. westbladi by using anti-tubulin antibodies, which stain neurotubules and thus reveal most of the NS, while previously, we have only visualized GYIRF-amide and 5-HT IR fibres. The new data is used to reconstruct the evolution of some features of the NS in Nemertodermatida and provide a reconstruction of ancestral states.

Here, we also provide a description of the body wall musculature in Sterreria sp., in addition to our previous thorough investigation of $M$. stichopi and $N$. westbladi (Meyer-Wachsmuth et al. 2013). Finally, the high-resolution differential interference contrast microscopy permitted us to better visualize some morphological characters of the species studied, such as statocysts, sperm and glands and, in combination with anti-tubulin staining, describe in detail the broom organ in F. cf. apelti. 


\section{Material and methods}

\section{Sampling and identification}

Specimens of the interstitial genera Flagellophora and Sterreria were extracted from sandy sediments collected between 1.5 to $32 \mathrm{~m}$ depths using $\mathrm{MgCl}_{2}$ anaesthetization. Nemertoderma lives on muddy bottoms, and specimens were isolated by siphoning off the uppermost layer of sediment through a $125-\mu \mathrm{m}$ sieve, in which the worms are caught. Species identification based on light microscopy is difficult due the scarcity of available morphological characters. Sterreria psammicola (Sterrer, 1970), for example, has recently been discovered to be a complex of cryptic species with mostly restricted but sometimes overlapping ranges (Meyer-Wachsmuth et al. 2014). A recent molecular phylogenetic study of Nemertodermatida showed that the genus Nemertoderma may also consist of more than two species and that the nominal species $N$. bathycola and $N$. westbladi have been confounded in the past (Wachsmuth and Jondelius 2015). Even though only one species of Flagellophora has been described so far, its cosmopolitan distribution and the cryptic diversity found in Nemertinoides and Sterreria (Meyer-Wachsmuth et al. 2014) give reason to believe that this species may also be a complex of cryptic species. Given these recent findings, we refrain from making definitive statements about species identities for the specimens used in this study. Given the sympatry observed in Nemertinoides and Sterreria, species identity can also not be inferred by geographic locality or habitat. Additionally, due to the fragility of the specimens, documentation of those intended for later morphological study is limited. The exact species identity of the specimens used in this study will possibly never be known. However, comparisons of the structure of the NS within Nemertodermatida are of interest even on the genus level, where we will show significant plasticity with this study.

For $F$. cf. apelti, 11 specimens were collected in 2010 from the La Maddalena archipelago, Italy and Waimanalo Beach, O'ahu, Hawai'i (Table 1).

Overall, 26 specimens of different species of Sterreria were collected at different localities in the La Maddalena archipelago, Italy (2010), around Helgoland, Germany (2011), the Madang lagoon, Papua New Guinea (2012) and off Faro, Portugal (2013) (Table 1).

About 40 specimens of $N$. cf. westbladi were collected from muddy bottoms at depths of 30-50 $\mathrm{m}$ in the vicinity of the Tjärnö and Kristineberg marine stations of the Sven Lovén Centre for Marine Sciences on the Swedish West coast from 2007 to 2012 (Table 1).

\section{Light microscopy in vivo}

Collected specimens intended for morphological studies are identified under the dissecting microscope in order to avoid damage by the application and subsequent removal of the coverslip necessary for microscope study; the animals are very small and fragile. Microphotographs of the squeezed and sometimes anaesthetized animals were taken of the whole animal and of potentially informative characters.

\section{Fixation, storage and pre-staining treatment}

Collected worms were fixed in HistoChoice ${ }^{\circledR}$ Tissue Fixative (Electron Microscopy Sciences Cat. 64115) or in Stefanini's fixative ( $2 \%$ paraformaldehyde and $15 \%$ picric acid in $0.1 \mathrm{M}$ Na-phosphate buffer at $\mathrm{pH}$ 7.6, Stefanini et al. 1967). The worms were stored for several weeks in the fixative then rinsed for $24-48 \mathrm{~h}$ in $0.1 \mathrm{M} \mathrm{Na}$-phosphate buffer $(\mathrm{pH} 7.6)$ containing $20 \%$ sucrose and processed as whole-mounts in Eppendorf tubes. Prior to staining, the animals were immersed in phosphate-buffer saline containing $0.4 \%$ Triton X-100 (PBS-T).

\section{Immunostainings}

Double stainings were carried out according to the indirect immunofluorescence method of Coons et al. (1955). The following antibodies and stains were used:

\section{Primary antibodies}

(a) Mouse anti-alpha tubulin conjugated with FITC (Sigma-Aldrich F-2168) dilution 1:100 in PBS-T

(b) Mouse anti-tyrosinated tubulin (Sigma-Aldrich T-9028) dilution 1:800 in PBS-T

(c) Rabbit anti-FMRFamide (Immunostar 20091) dilution 1:400 in PBS-T

(d) Goat anti-5HT (Immunostar 20079) dilution 1:400 in PBS-T

2. Secondary antibodies

(a) Sheep-anti-mouse FITC (Sigma-Aldrich F6257) dilution 1:40 in PBS-T

(b) Swine-anti-rabbit TRITC (DACO R0156) dilution 1:40 in PBS-T

(c) Donkey-anti-goat Alexa Fluor ${ }^{\circledR} 488$ (Abcam ab150129) dilution at 1:400 in PBS-T

3. F-actin histological staining

(a) Phalloidin-TRITC (Sigma-Aldrich P1951) dilution 1:100 in PBS

(b) Phalloidin-FITC (Sigma-Aldrich P5282) dilution 1:100 in PBS 
Table 1 Locality information for specimens included in this study with geographic coordinates and notes about habitat

\begin{tabular}{llrlll}
\hline Country & Locality & Latitude & Longitude & Species & Species \\
\hline Germany & Helgoland; Nordostmauer & 54.1887 & 7.8852 & Fine clean sand & Sterreria sp. \\
& Helgoland; Tonne 2 & 54.1802 & 7.9321 & Fine clean sand & Sterreria sp. \\
Italy & Budelli Island & 41.2934 & 9.3610 & Medium fine sand & Flagellophora cf. apelti, Sterreria sp. \\
& La Maddalena & 41.2808 & 9.3207 & Medium fine sand & Sterreria sp. \\
Lapua New Guinea & Panab Island & 41.2252 & 9.3765 & Coarse sand & Flagellophora cf. apelti, Sterreria sp. \\
& Wanad Island & -5.1717 & 145.8081 & Medium fine sand & Sterreria sp. \\
Portugal & Faro & 36.1353 & 145.8211 & Fine sand some organic content & Sterreria sp. \\
& Lilleskär-slätten & 58.8821 & 11.1096 & Fine mud & Sterreria sp. \\
& Syd Hällsö & 58.9449 & 11.0825 & Fine mud & Nemertoderma sp. \\
& Essvik & 58.2843 & 11.5223 & Fine mud & Nemertoderma sp. \\
USA & Telekabeln & 58.2585 & 11.4401 & Fine mud & Nemertoderma sp. \\
\hline
\end{tabular}

Incubations were performed with a cocktail of two different primary antibodies not produced in the same animal, for 24 $72 \mathrm{~h}$ at $+11{ }^{\circ} \mathrm{C}$. Most often, the worms were stained with a combination of mouse anti-alpha tubulin and rabbit antiFMRFamide, less frequently combinations of mouse antityrosinated tubulin and rabbit anti-FMRFamide, or goat anti5HT and rabbit anti-FMRFamide were used. After a thorough rinse in PBS-T, the corresponding secondary antibodies were applied one after another for $1 \mathrm{~h}$ each on a shaker at room temperature. Sometimes, worms were single-stained in one of the primary antibodies or single- or double-stained with phalloidin. After rinsing $3 \times 5 \mathrm{~min}$ in PBS, the animals were mounted in Vectashield mounting medium and stored in the dark at $-20{ }^{\circ} \mathrm{C}$.

As a control for specificity, some animals were incubated for a week in PBS-T solution alone without the primary antibodies, before the secondary antibodies were applied in the usual way. No staining of the NS was obtained in controls.

\section{Confocal microscopy}

The animals were examined in a confocal laser scanning microscope (CLSM) LEICA TCS SP5 of the Research Resource Center for molecular and cell technologies of St.-Petersburg State University. Some specimens were viewed from the dorsal side, some from the ventral side. Usually, 25-60 optical sections were obtained while scanning through the specimen. The maximum projection option was used to make reconstructions from several adjacent optical sections in a series or from a whole series (thus resulting in a thicker optical section). The files obtained were processed with the Leica LAS AF lite software, as well as Graphic Converter v. 7.6. and Adobe Photoshop v. 7.0.

\section{Results}

\section{Flagellophora cf. apelti}

\section{General morphology}

$F$. cf. apelti is a small interstitial worm, up to $1 \mathrm{~mm}$ long, living in the sub- and lower littoral in coarse to fine sand. Most of the investigated specimens were sexually mature, possessing eggs and sperm packages, as well as a dorsal bursa (Fig. 1ad). The most striking feature of this species is the proboscis, or broom organ, in the anterior, about one third of the body length (Fig. 1a). It passes ventrally very close to the statocyst, in squeeze preparation often bending around it (Fig. 1a, b). When the broom organ is retracted, its distal end lies at a distance of $150 \mu \mathrm{m}$ (Fig. 1b) from the frontal pore, through which it can be protruded, while the statocyst lies at a distance of $200 \mu \mathrm{m}$ from the frontal pore.

The space between the frontal pore and the statocyst is occupied by frontal glands. The statocyst is oval, $22.5 \times$ $20.5 \mu \mathrm{m}$. Two smooth statoliths $9 \mu \mathrm{m}$ in diameter lie close to

Fig. 1 Light microscopic differential interference contrast pictures of Flagellophora cf. apelti. a Overview of the living animal, showing broom organ, frontal pore, statocyst, parenchyma, dorsal bursa, eggs and sperm packages. b Retracted broom organ (asterisk marks its distal end) and statocyst. c Bilithophorous statocyst with smooth-looking stones. One of the muscles attaching the statocyst to the body wall is visible on the right side. d Bursa with mouthpiece (see insert for details), two eggs, some sperm packages and male opening in subterminal position. e Anterior end of the body, broom organ opening. $f$ Epidermis of the dorsal posterior end of the body. Note polygonal shapes of the epidermal cells and granular aggregation within each cell (arrows). bo broom organ, bs bursa, eg egg, $f g n$ frontal gland necks, $f p$ frontal pore, $\operatorname{lm} f$ lateral muscle fibres, mo male opening, $s p$ sperms, st statocyst 


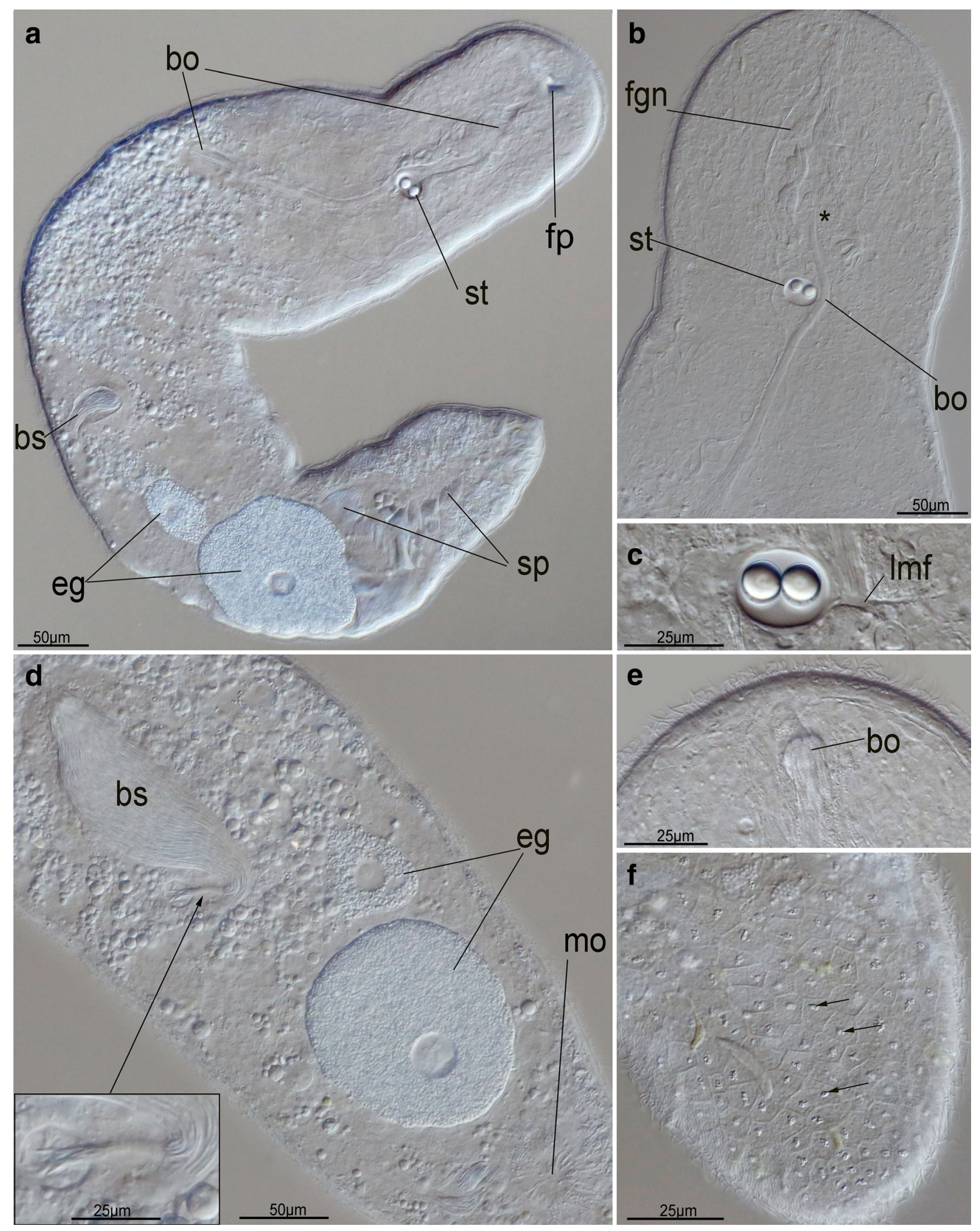



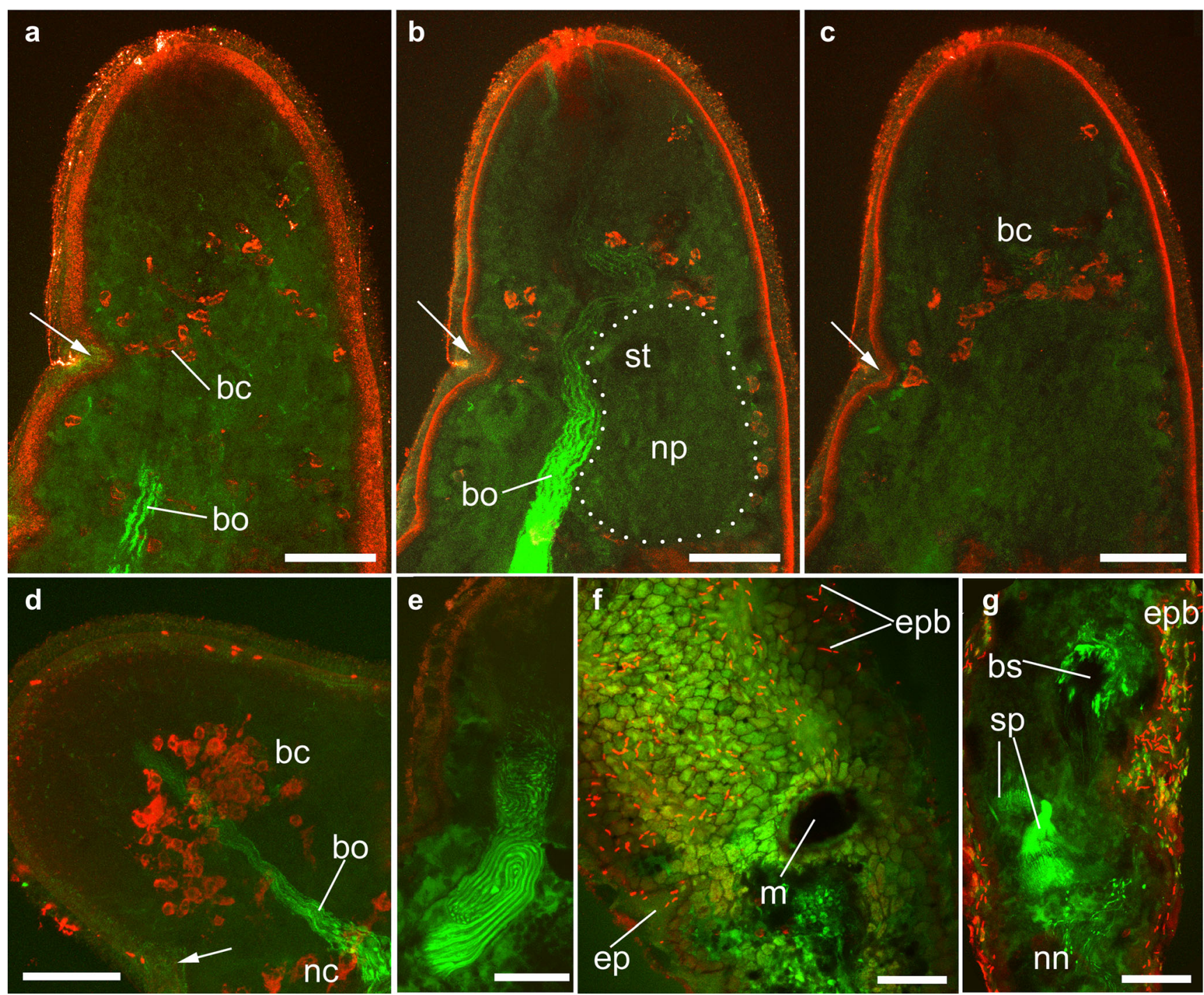

Fig. 2 Confocal laser scanning microscope images of double-stained specimens of Flagellophora cf. apelti. Double staining of alpha-tubulin IR (green) and FMRFamide IR (red) elements. a-c Sagittal optical sections through the anterior end of the body of the same specimen. Dorsal side is on the right. Note the median broom organ, passing ventrally of the statocyst, the unstained area on the right that presumably contains the brain neuropile and an aggregation of FMRFamide IR brain cells around it, mostly anterior to it. The apparent FMRF-amide staining of the epidermis is an artefact resulting from the high-intensity scans necessary due to the comparative weakness of the red fluorescence to that of alpha-tubulin; it is missing in Fig. 2d. d Anterior

each other (Fig. 1c). The frontal pore lies about $20 \mu \mathrm{m}$ from the anterior body tip (Fig. 1e).

The female bursa, which is present in all species of the family Ascopariidae, opens dorsally approximately in the third quarter of the body length, anterior to both the eggs and the sperm packages (Figs. 1a, d). The bursa is retortshaped and has a distinct mouthpiece about $30 \mu \mathrm{m}$ long, not observed previously (Fig. 1d, insert).

In the posterior region of the body, epidermal cell borders are clearly visible (Fig. 1f). The cells have polygonal, often

end of the body, tubulin IR broom organ is surrounded by a compact aggregation of FMRFamide IR nerve cells at the level of the statocyst. Note the tubulin IR nerve net in the epidermis (arrow). e Anterior end, the broom organ is composed of coiled tubulin IR strands. f Unspecific staining of the epidermis at mid-body revealing the mouth opening. Borders of polygonal epidermal cells are readily visible; note gland cell openings between the cells. Also note red-stained epidermal bacteria. $\mathbf{g}$ Posterior end, dorsal retort-shaped bursa and sperm aggregations. Note epidermal bacteria. Scale bars $25 \mu \mathrm{m}$. $b c$ brain cells, bo broom organ, $b s$ bursa, ep epidermis, epb epidermal bacteria, $m$ mouth, $n c$ nerve cells, $n n$ nerve net, $n p$ neuropile, $s p$ sperms, $s t$ statocyst

hexagonal, shapes and each has an aggregation of granular material in the middle, which looks like a luminous spot under a light microscope.

\section{Broom organ structure and other peculiar features}

The broom organ has been visualized by anti-alpha-tubulin immunostaining (Figs. 2a, b, d, e and 3d-f) and by phalloidin staining of muscles (Figs. 3i, j). It always shows a quite strong tubulin immunoreactivity, especially in the proximal part (Figs. 2d, e), 


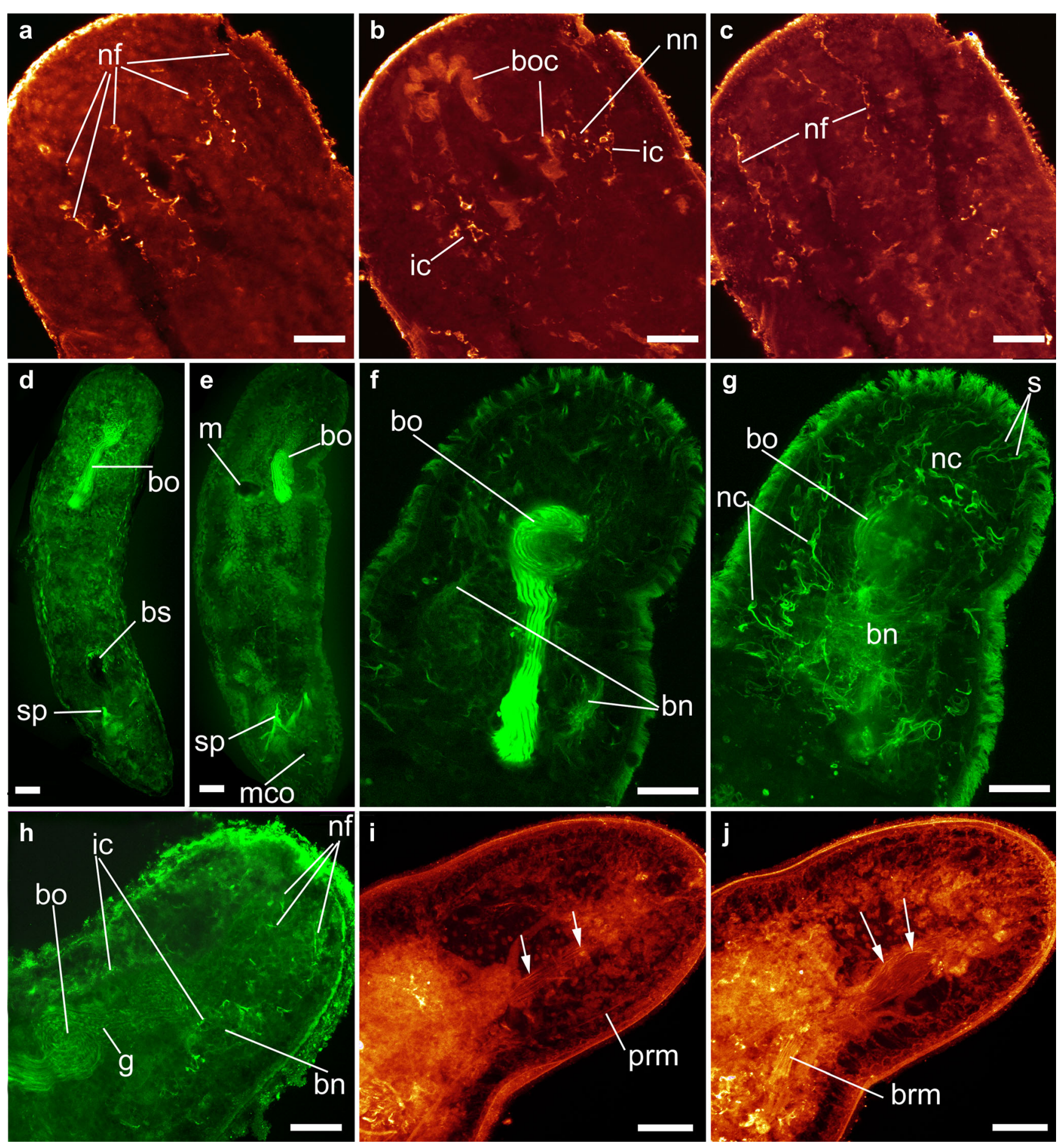

Fig. 3 Confocal laser scanning microscope images of Flagellophora $\mathrm{cf}$. apelti. a-c FMRFamide IR pattern in the anterior end of the body and broom canal innervation. Note rather large unstained cells lining the canal and FMRFamide IR local nerve nets around the canal in b. d-g Apha-tubulin IR pattern. d Overview of the dorsal side of a specimen with broom organ, bursa, sperm packages. e Overview of the ventral side showing the mouth opening and subterminal male copulatory organ. $\mathbf{f}$ Broom organ, note the parallel tubulin IR strands in its proximal part and the coiled strands in the distal part. $\mathbf{g}$ Another optical section of the same animal, showing a wide brain neuropile enveloping the proximal part of the broom. Note the presence of numerous neurons with long processes surrounding the brain on the outside. Also note a group of IR neurons near the distal end of the broom. $\mathbf{h}$ 5-HT IR elements of the anterior part of the body, dorsal side on the right. Note immunoreactivity in the neuropile, along the borders of the broom organ canal, and in the anterior region of the body. i Phalloidin staining of the anterior part of the body. Note F-actin fibres forming a sheath around the broom (arrows) and parenchymal longitudinal muscles retractors of the anterior end. $\mathbf{j}$ Another optical section of the same phalloidin-stained specimen, showing more of the muscular broom sheath (arrows) as well as the strong specialized muscle retractor of the broom, connecting its proximal end to the body wall. Scale bars $25 \mu \mathrm{m}$. bn brain neuropile, bo broom organ, boc broom organ canal, brm broom retractor muscle, $b s$ bursa, $g$ granules, ic innervation of the broom canal, $m$ mouth, mco male copulatory organ, $n c$ nerve cells, $n f$ nerve fibres, $n n$ nerve net, $p r m$ parenchymal retractor muscle, $s$ sensory cells, $s p$ sperms, $s t$ statocyst 
and about ten individual IR strands are clearly distinguishable inside of it (Figs. 2b, d, e and 3d, f). Each one seems to run along the whole length of the broom organ. The broom can be more or less extended or compactly coiled. In the latter case, it is interesting to note that the proximal part of the broom remains rather straight, while the coils appear in the distal part, anterior to the level of the statocyst (Figs. 2e and 3f). The most tightly coiled broom organ in our material (Fig. 2e) had only one fourth of its length, the most proximal part, straight, before it bent in on itself and in the most distal part the individual strands within the broom became coiled (Fig. 2e). At the proximal end, the individual strands of the broom seem to break apart into numerous thinner fibres (Fig. 2e). When the broom organ is not stained by anti-tubulin antibody, obscuring the view, numerous very small granules $(1 \mu \mathrm{m})$ can be observed along the broom strands (Fig. 3h). The broom lies and moves within a canal-a tube starting at the frontal pore and ending in the vicinity of the gut. The canal lumen is lined by relatively large (up to $25 \mu \mathrm{m}$ long), likely glandular cells and their processes, unstained by the antibodies used (Fig. 3b).

The phalloidin-TRITC staining revealed a sheath of phalloidin-stained F-actin fibres enveloping the broom; thus, the broom itself becomes contractible (Figs. 3i, j). A strong specialized muscle retractor connects the proximal end of the broom to the body wall (Fig. 3j). In addition, there are some parenchymal longitudinal muscles - retractors of the anterior end of the body (Fig. 3i).

Anti-tubulin immunostainings also permitted to visualize the general layout of the body from the dorsal side (Fig. 3d) with the anterior broom organ, dorsal bursa and caudal sperm packages and from the ventral side (Fig. 3e) with a male pore in the posterior and a mouth opening. The mouth opening lies ventrally, not far from the proximal end of the broom organ, and could be detected for the first time in this species (Fig. 3e). Epidermal cells around the mouth display peculiar polygonal shapes but the very rim of the mouth is smooth (Fig. 2f).

Surprisingly, in the Hawaiian specimens, the antiFMRFamide antibody also stained epidermal bacteria, tiny rod-shaped organisms, 2-5 $\mathrm{m}$ long, abundant in the epidermis (Figs. 2f, g).

Nervous system of F. cf. apelti

The NS patterns have been visualized by double antiFMRFamide/anti-alpha-tubulin immunostaining (Fig. 2), by single anti-FMRFamide staining (Figs. 3a-c), single antialpha-tubulin staining (Figs. 3d-g) and single anti-5HT staining (Fig. 3h).

Anti-alpha-tubulin immunostaining always reveals the broom organ, which is so bright, that it dominates the weaker reaction stainings and makes them indiscernible.
We were able to sufficiently counter this effect only in single anti-alpha-tubulin immunostainings, which show more details than anti-tubulin in double stainings. Thus, a single anti-alpha-tubulin immunostaining revealed an anterior centralisation of the NS in form of a large neuropile (Fig. 3g), which lies dorsal to the broom organ, slightly posterior to the statocyst. The lateral borders of the neuropile are wrapped around the broom organ; thus, they are visible on the optical sections through the broom, on the sides of it (Fig. 3f). The statocyst seems to be embedded into the neuropile on the dorsal and posterior sides (Fig. 2b). Surrounding the neuropile is a large number of unipolar and bipolar neurons, 3-5 $\mu \mathrm{m}$ in size, connected to the neuropile and interconnected between each other by nerve fibres (Fig. 3g). Numerous fibres with cell bodies along their course go to the anterior end of the body, most likely sensory cells.

Anti-FMRFamide immunostaining reveals numerous IR cells around the area of the neuropile (Figs. 2a-c) forming a loose brain. On serial sagittal sections, it is visible that the FMRFamide IR cells are scattered on the periphery of the neuropile (Fig. 2a), dorsally from it (Fig. 2b), but mostly anterior to it, surrounding the broom organ canal (Figs. 2a-c). Sometimes, FMRFamide IR cells can be seen forming a separate aggregation around the broom canal (Fig. 2d). The FMRFamide IR brain cells are mostly bipolar or multipolar neurons, about $5 \times 3 \mu \mathrm{m}$ in size; thus, they are likely present among the numerous tubulin IR cells visualized around the neuropile in Fig. $3 \mathrm{~g}$.

Double stainings of nerves and muscles were unfortunately not successful. The neuropile and most of surrounding cells appear to be submuscular, while the dorsal nerve cells and the cells posterior to the brain may lie within the epidermal layer.

Single anti-FMRFamide staining of Stefanini-fixed specimens of $F$. cf. apelti visualized the innervation of the anterior end of the body and the broom organ canal (Figs. 3a-c). Five longitudinal chains of FMRFamide IR neurons have been detected on one side of the body, about four on the other side, a distinction between ventral and dorsal was not possible. They run alongside the central canal of the broom organ on all sides. Some of the nerve cells send projections to the cells lining the canal (Fig. 3b). Sometimes, small local nerve nets appear by the canal walls (Fig. 3b). FMRFamide IR cells of the anterior fibres are about $5.5 \times 2.5 \mu \mathrm{m}$ in size. What appear to be smaller cells are most likely varicosities.

Anti-5-HT immunostaining reveals IR elements in the neuropile, and a few IR neurons $4 \mu \mathrm{m}$ in diameter on the borders of the neuropile, mostly in front of it (Fig. 3h). Some 5-HT IR fibres were detected in front of the neuropile, innervating the anterior end of the body. The most noticeable feature of the 5-HT pattern is the innervation of the broom canal, which is lined on all sides by 5-HT IR fibres (Fig. 3h). 


\section{Sterreria spp.}

\section{General morphology}

Species of the genus Sterreria spp. are small interstitial worms usually up to $5 \mathrm{~mm}$ in length, with a length to width ratio of approximately 15:1 (Fig. 4a). At the anterior end, there is a bilithophorous statocyst with a lithocyte capping the statolith appearing in blisters (Fig. 4b), one of characteristics of the family Nemertodermatidae (Sterrer 1998). Usually, the "blister cap" stays on top of the statoliths even when the animal is turned; only when the animal is squeezed hard, as in Fig. 4c, it becomes visible that the blistered structure is a feature of the cytoplasm of the lithocyte, not of the statolith itself, which is smooth. The statocyst measures $23 \times 16 \mu \mathrm{m}$, with the stones $8 \mu \mathrm{m}$ in diameter. The stones lie well apart from each other and there is a hint of partition between them (Fig. 4c). Frontal glands described by Faubel (1976), Sterrer (1998) and Lundin (2000) for S. psammicola and S. rubra (Faubel, 1976) can be observed in the species studied (Fig. 4b).

The male copulatory organ lies in supraterminal position, just anterior to the caudal adhesive plate (Fig. 4a). The male opening is lined by numerous rhabdoids (Fig. 4d). The copulatory organ consists of a false seminal vesicle, as it lacks its own walls, but is composed of tightly packed autosperm with a small penis cone distally (Fig. 4d). Autosperm and allosperm are quite different morphologically, as is the case in most nemertodermatids (Sterrer 1998). Cells of autosperm can be observed both in the false seminal vesicle and outside the body, by the male opening (Fig. 4d). They are longer, have a smooth surface and look rigid as opposed to allosperm cells, which are much shorter, less rigid and display a helical structure on the surface (Fig. 4c). As seen in Fig. 4c, allosperm cells can be observed in rather incongruous areas, supporting the view that insemination occurs via epidermal injection.

\section{Nervous system}

The NS of Sterreria spp. has been visualized by anti-alphatubulin (Figs. 5a-c), anti-5-HT (Figs. 5g-i) and by antityrosinated-tubulin (Figs. 5j, k) immunostainings as well as by double immunostaining of alpha-tubulin IR and FMRFamide IR elements (Figs. 5d-f). The NS consists of a basiepidermal nerve net and a rather complex brain, which, as

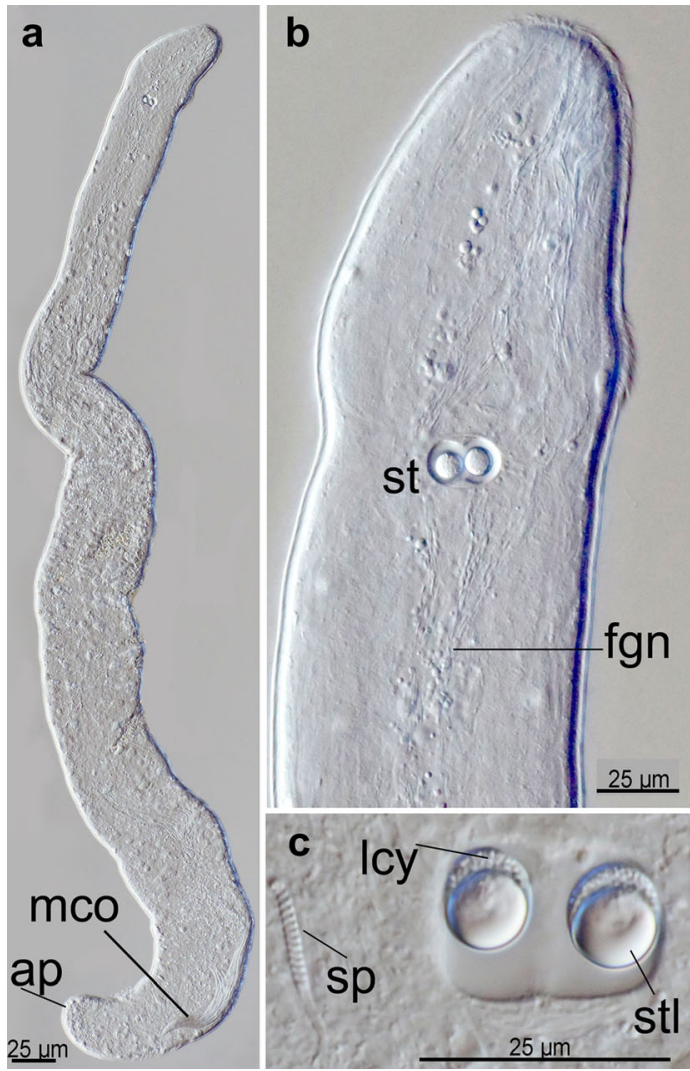

Fig. 4 Light microscopic differential interference contrast micrographs of Sterreria sp. a Overview of the living animal, showing its elongated body shape. The animal is slightly twisted and the posterior end viewed from the left lateral side. Note dorsal supraterminal male copulatory organ and adhesive plate. $\mathbf{b}$ Anterior end of the body showing frontal glands and brain cells. c Statocyst of a hard squeezed specimen with two statoliths

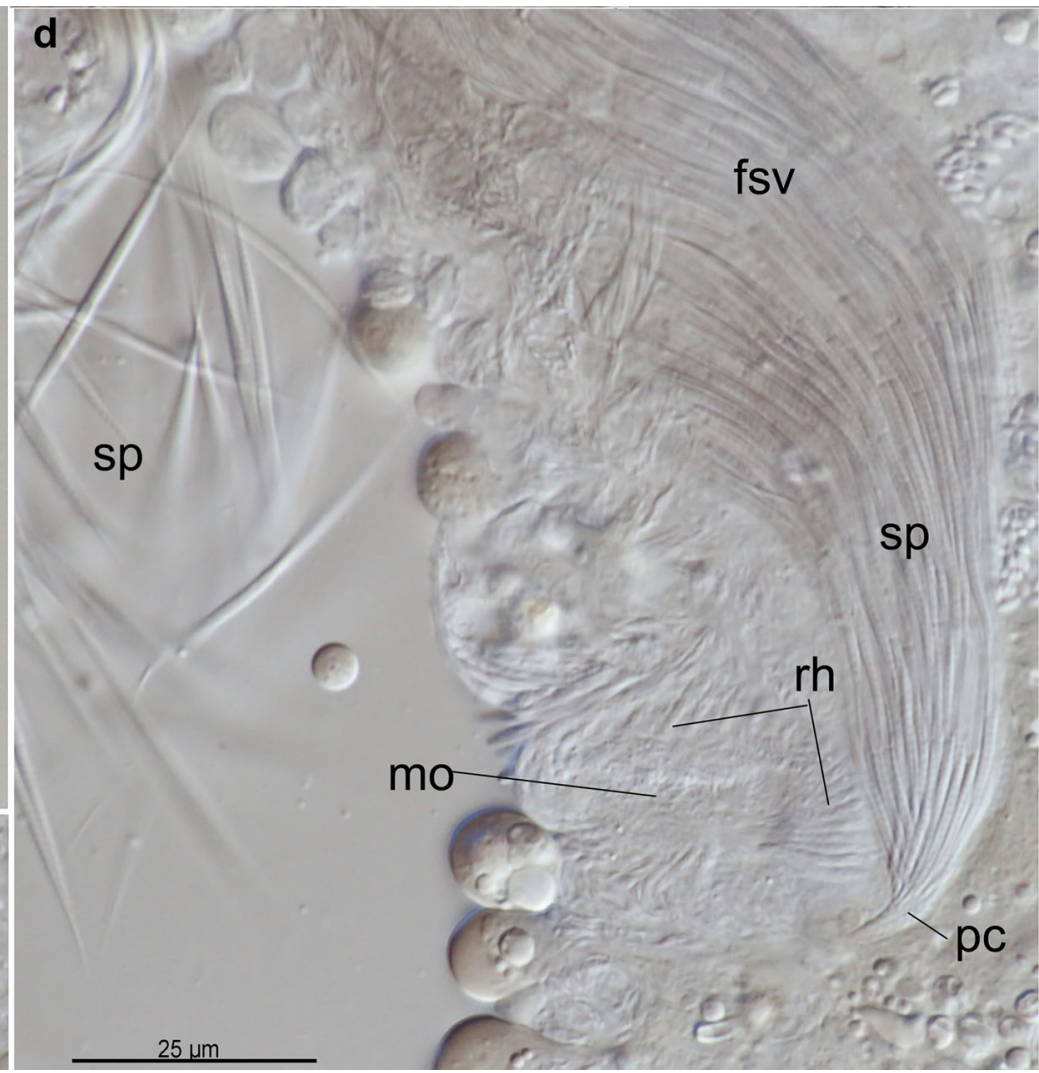

and lithocytes with blistered-looking cytoplasm. Note allosperm lying close to statocyst. d Male opening, lined by rhabdoids, penis cone and false seminal vesicle composed of closely packed autosperm. Note sperm outside the body as well. ap adhesive plate, $f g n$ frontal gland necks, $f_{s} v$ false seminal vesicle, lcy lithocyte, mco male copulatory organ, mo male opening, $p c$ penis cone, $r h$ rhabdoids, $s p$ sperms, $s t$ statocyst, $s t l$ statolith 


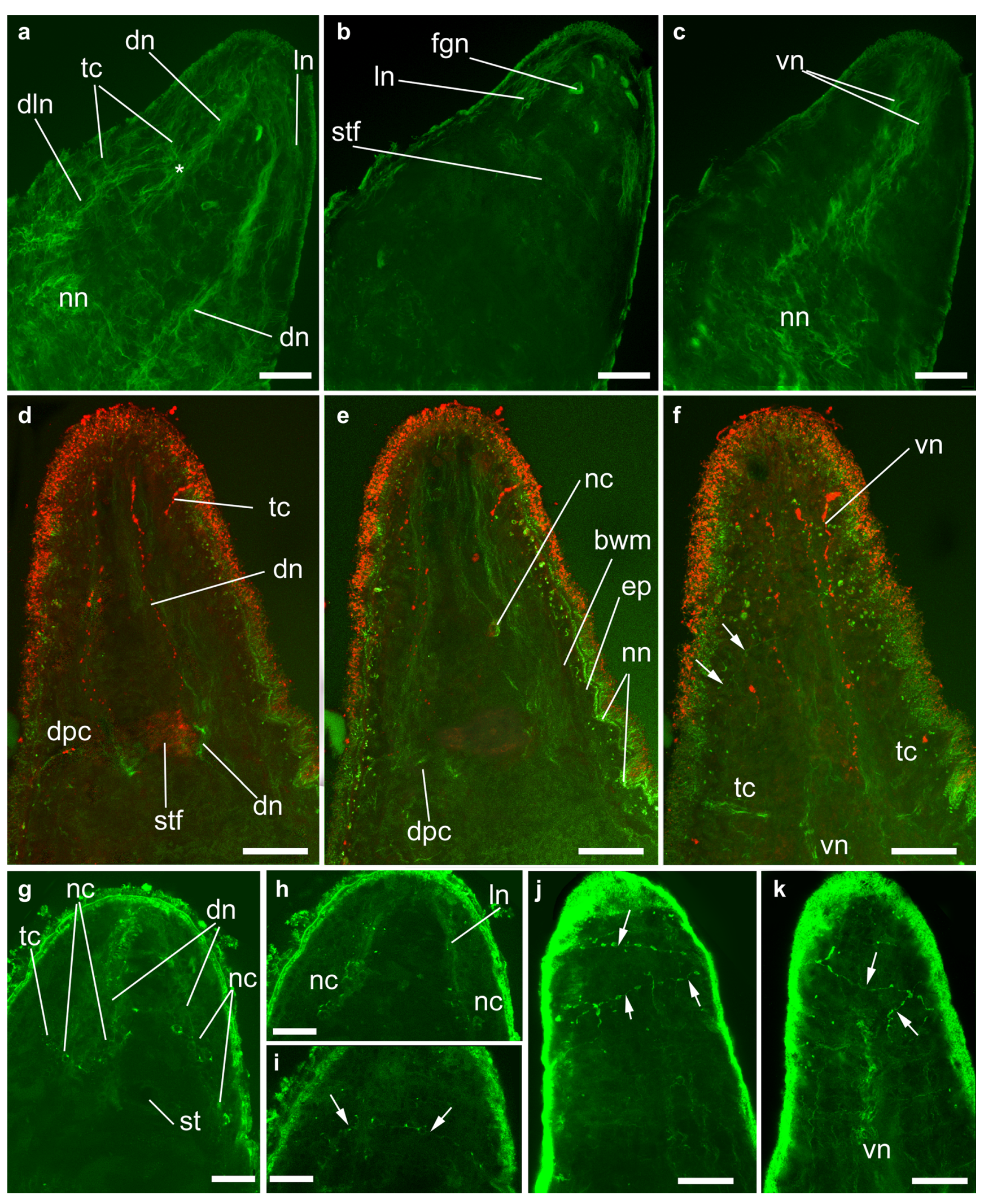

far as we can tell without a double tubulin-phalloidin staining, lies entirely below the level of the body wall musculature (Fig. 5e).
Alpha-tubulin immunoreactivity was observed around and anterior to the level of the statocyst. The statocyst in fixed animals lies at the distance of $80-100 \mu \mathrm{m}$ from the anterior tip of the 
4 Fig. 5 Confocal laser scanning microscope images of Sterreria sp. a-c Alpha-tubulin IR elements of dorsal side (a), midline region (b) and ventral side (c) of the same specimen. The brain is basket-shaped with dorsal, dorso-lateral and lateral neurite bundles in a, lateral neurite bundles in $\mathbf{b}$ and ventral neurite bundles in c. Asterisk marks the fork in dorsal neurite bundles, where dorso-lateral neurite bundles originate. Note the nerve elements around the statocyst in $\mathbf{b}$ as well as sections of frontal gland necks brightly stained because of microtubule lining. $\mathbf{d}-\mathbf{f}$ Double staining of alpha-tubulin IR (green) and FMRFamide IR (red) elements. Optical sections of the dorsal side (d), the midline (e) and the ventral side (f) of the same specimen. Note FMRFamide IR nerve fibres around the statocyst and their connection with dorsal neurite bundles, which also contain some FMRFamide IR nerve fibres. The ventral neurite bundles (in f) and some transversal commissures show FMRFamide IR fibres. Note also FMRFamide-negative basiepidermal nerve net and unstained layers of body wall muscles in e. In $\mathrm{f}$ arrows mark irregular transverse fibres, like those in $\mathbf{j}$ and $\mathbf{k . g}$ 5-HT IR neurons in the dorsal neurite bundles by the statocyst. h 5-HT IR cells in lateral neurite bundles of the same specimen. i 5-HT IR nerve fibre on the ventral side of the same specimen, marked by arrows. $\mathbf{j}$, $\mathbf{k}$ Tyrosinated-tubulin IR on the dorsal side $(\mathbf{j})$, on the ventral side (k) indicated by arrows. Scale bars $25 \mu \mathrm{m}$. bwm body-wall muscles, $d l n$ dorso-lateral neurite bundles, $d n$ dorsal neurite bundles, $d p c$ dorsal posterior commissure, ep epidermis, fgn frontal gland necks, $\ln$ lateral neurite bundles, $n c$ nerve cells, $n n$ nerve net, st statocyst, $s t f$ statocyst nerve fibres, $t c$ transversal commissure, $v n$ ventral neurite bundles

body (Fig. 5b), while the brain structure occupies the anterior 170-190 $\mu \mathrm{m}$ of the body (Fig. 5a). The brain resembles a loosely woven basket, stronger dorsally, with the opening directed posteriorly (Figs. 5a-f). In the brain, the most prominent fibres are two dorsal longitudinal neurite bundles (Fig. 5a). At about the level of the statocyst, each of those forks into a dorsal and a dorso-lateral neurite bundle (Fig. 5a). A pair of lateral longitudinal neurite bundles can be observed running parallel to the dorsal bundles (Fig. 5a, b). Close to the anterior tip of the body, these lateral bundles appear thicker than the dorsal ones, though the fibres composing them are more loosely packed (Fig. 5b); more posteriorly, the lateral bundles become weaker than the dorsal ones (Fig. 5a). The dorsal and lateral longitudinal neurite bundles are interconnected by seven to eight thin irregular commissures, composed of one to four nerve fibres each (Fig. 5a). Towards the posterior opening of the basket, the structure becomes more and more irregular, resembling at this level a dense nerve net (Fig. 5a). On the ventral side, two adjacent longitudinal neurite bundles run from the anterior tip of the animal to the anterior end of the basket-like structure (Fig. 5c). The transverse fibres connecting them with the lateral bundles are weak and lie very close to the surface (Fig. 5f). The statocyst is hard to detect because the nerve fibres around it are usually weakly stained (Fig. 5b). It lies at the same level as the branching of the dorsal neurite bundles and seems to be connected both with the dorsal bundles (Fig. 5d, e) and the transverse commissure, which are connecting just posterior to the statocyst. By analogy with the acoel brains, we call this commissure dorsal posterior commissure (Fig. 5d).

FMRFamide immunoreactivity has been detected in the dorsal neurite bundles of the brain structure (Fig. 5d). Only a few of the numerous anti-tubulin IR fibres are FMRFamide IR. These dorsal fibres run from the anterior end of the body to the statocyst, but no further. A few FMRFamide IR fibres are also found in the lateral neurite bundles (Fig. 5e), while on the ventral side of the animal, the FMRFamide IR fibres are more numerous (Fig. 5f). The FMRFamide immunoreactivity is also detected in the nerve aggregation surrounding the statocyst (Fig. 5d, e) and in some commissures, including the dorsal posterior one (Fig. 5d).

5-HT immunostaining proved to be rather weak, but 5-HT IR clusters of nerve cells were detected in the dorsal and lateral neurite bundles of the brain as well as in some commissures (Fig. $5 \mathrm{~g}-\mathrm{i}$ ). The neurons, $5-8 \mu \mathrm{m}$ in diameter, lie along the dorsal and lateral neurite bundles, anterior to the statocyst (Fig. 5g, h). The neurons in the ventral commissure are about 4-5 $\mu \mathrm{m}$ in diameter (Fig. 5i). 5-HT immunoreactivity was not detected in nerve fibres surrounding the statocyst (Fig. $5 \mathrm{~g}$ ).

Tyrosinated-tubulin immunostaining permitted us to better visualize the IR elements closer to the surface (Fig. 5j, k). Both on the dorsal (Fig. 5j) and the ventral (Fig. 5k) sides of the body, irregular chains of small bipolar neurons were detected. The neurons are about $3 \mu \mathrm{m}$ long and 1.5-2 $\mu \mathrm{m}$ wide and do not show either 5-HT or FMRFamide immunoreactivity. They were, however, also detected by anti-alpha-tubulin immunostaining (Fig. 5f).

\section{Muscular pattern}

Phalloidin staining of the musculature of Sterreria spp. (Fig. 6a-g) revealed body wall musculature composed of an orthogonal grid of circular and longitudinal muscles (Fig. 6ac). In the anterior quarter of the body length, there is an additional layer of diagonal muscles (Fig. 6a). Those are intermingled with the circular ones and clearly originate from them. It is easy to follow how one transverse muscle fibre continues as circular, while the adjacent one takes a diagonal course (Fig. 6a). Diagonal muscles criss-cross each other at an angle of about $120^{\circ}$. The inner longitudinal muscles near the midline of the body form a hiatus at the anterior end, with about 4-5 longitudinal muscles from the right and the left side crisscrossing each other (Fig. 6a). Towards the middle of the body, diagonal muscles disappear and only a regular orthogonal grid remains (Fig. 6b). Individual fibres of the circular musculature are much weaker than fibres of the longitudinal and diagonal musculature.

At the posterior end of the body, Sterreria species have a subterminal adhesive plate formed by a line of closely packed gland necks opening to the surface (Figs. 6c, f, g). The ventral and dorsal longitudinal muscles form anastomoses and attach to each other near the borders of this glandular stripe (Fig. 6f, g).

In none of the studied specimens, a mouth could be observed. Most of the specimens were male mature and it has

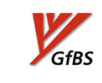



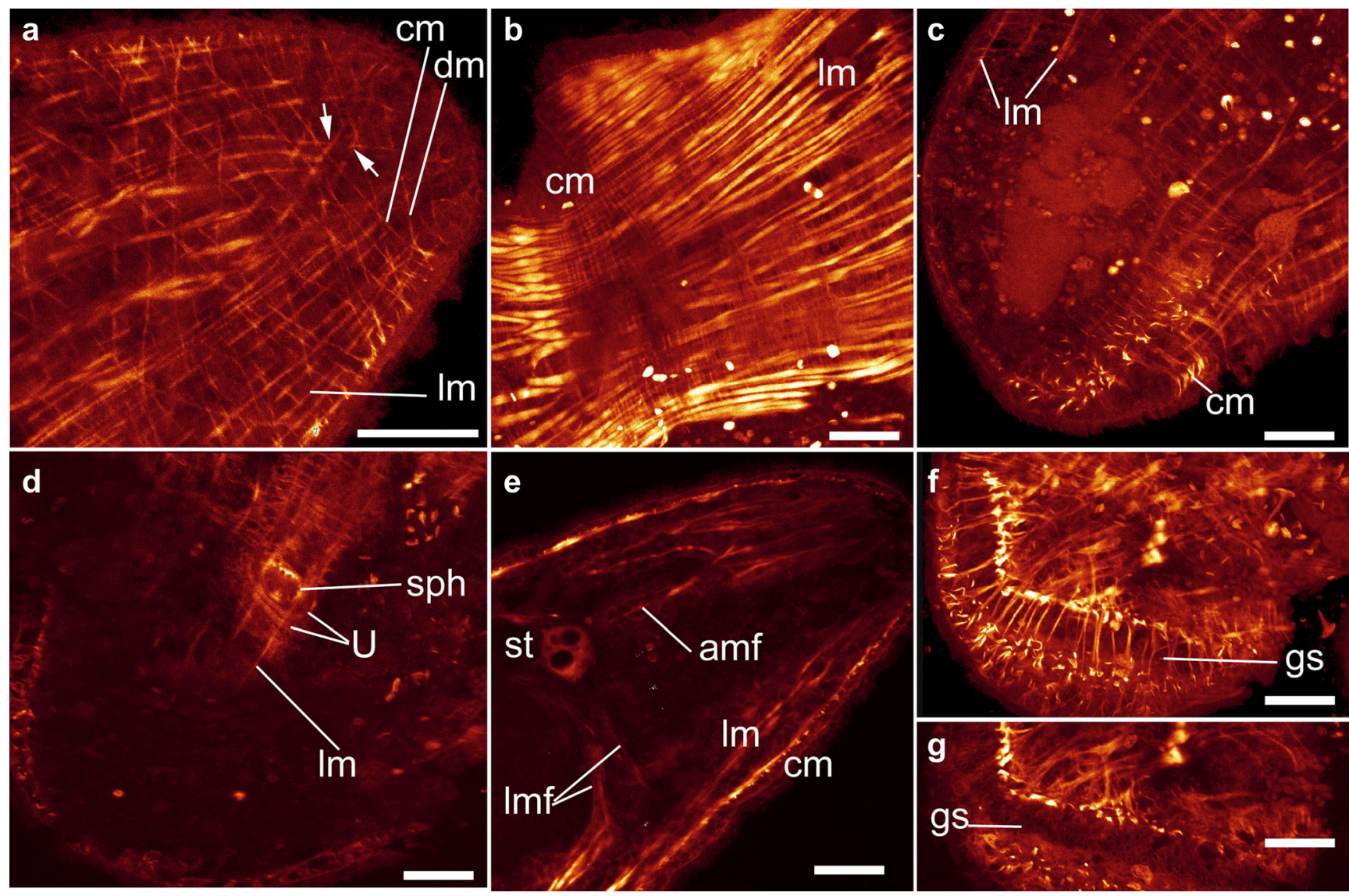

Fig. 6 Confocal laser scanning microscope images of Sterreria sp. stained with phalloidin-TRITC. a Anterior end with diagonal, circular and longitudinal muscles of the body wall. Note the anterior hiatus of longitudinal muscles (arrows). b Mid-body, the body wall comprises only weak circular and strong longitudinal muscles. Arrowheads point to anastomoses between longitudinal muscles. $\mathbf{c}$ Posterior end of the body with longitudinal and circular musculature at the level of the adhesive plate. $\mathbf{d}$ Male opening on the dorsal side near the posterior end of the body

been shown that the mouth in $N$. westbladi completely reduces in older animals (Westblad 1937, MeyerWachsmuth et al. 2013) and it is thought to do be the case in Sterreria as well (Hooge 2001). Instead, we were able to visualize the muscle arrangement around the male opening (Fig. 6d). It is located dorsally, close to the posterior end of the body. There are one to two sphincter fibres encircling the opening. The most median longitudinal body wall muscles bend around the male opening and continue caudally while two to three more lateral ones bend around the male opening in U-shaped fashion. Circular muscles simply bend out of the way.

The inner musculature is mostly comprised of the fibres around the statocyst (Fig. 6e), which is shifted dorsally and suspended by strong muscles originating from the lateral sides of the body wall from both sides (Fig. 6e). Seemingly, the dorsal posterior commissure of the brain described above runs along these muscles. Several muscle fibres reach the statocyst from the anterior end of the body (Fig. 6e). with muscular sphincter and U-shaped muscles from the anterior. e Inner muscles of the anterior end of the body supporting the statocyst. $f$ Muscles at the posterior end of the body. Ventral side up. $\mathbf{g}$ Another optical section of the same series showing a stripe of gland openings at the posterior end. Scale bars $25 \mu \mathrm{m}$. amf anterior muscle fibres, $\mathrm{cm}$ circular muscles, $\mathrm{dm}$ diagonal musculature, $g s$ glandular stripe, $\operatorname{lm}$ longitudinal muscles, $\operatorname{lm} f$ lateral muscle fibres, $s p h$ sphincter, st statocyst, $U$ U-shaped muscles

\section{Nemertoderma cf. westbladi}

\section{Nervous system and gland innervation}

The NS of $N$. cf. westbladi is entirely basiepidermal. It was studied by anti-alpha-tubulin immunostaining (Figs. 7a, c, d and $8 \mathrm{a}, \mathrm{b}, \mathrm{e})$ and anti-tyrosinated-tubulin immunostaining (Figs. $7 b$ and $8 c, d$ ).

Anti-alpha-tubulin immunostaining readily reveals general morphology as it not only stains nerve cells but also cilia, sperm (Fig. 7a), the male copulatory organ (Fig. 7a) and all glands with gland necks lined by microtubules (Fig. 8).

At the anterior end of the animal, there is a nerve ring surrounding a bilithophorous statocyst. From this ring, several caudal neurite bundles originate (Fig. 7a, b) but only the two ventral ones reach the posterior end of the animal (Fig. 7c, d). At the site of origin of the ventral neurite bundles, the brain ring is noticeably thickened, forming a local neuropile 


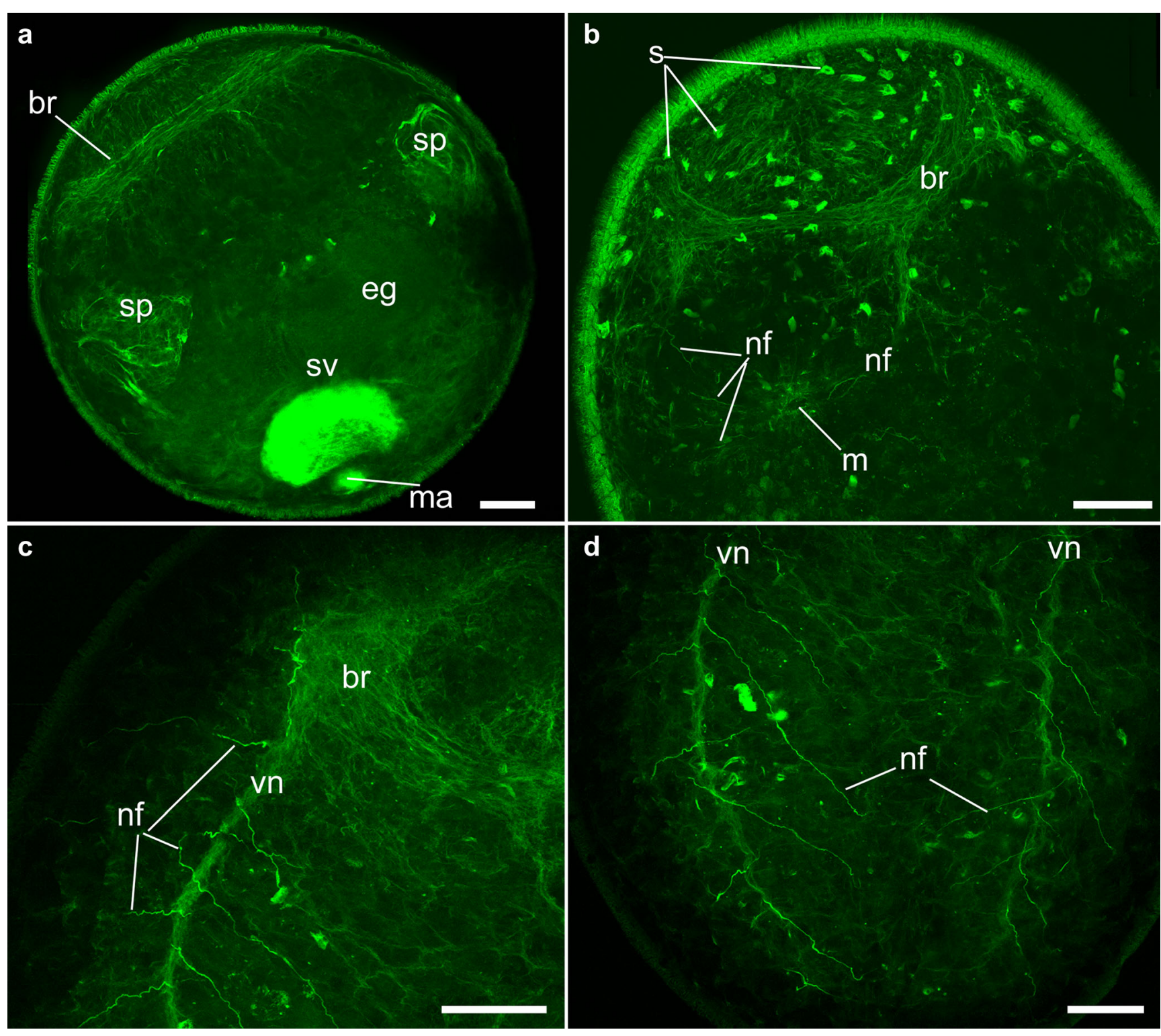

Fig. 7 Confocal laser scanning microscope images of Nemertoderma cf. westbladi. a Alpha-tubulin immunoreactivity. Overview of a roundish male mature animal with ring-shaped brain, paired lateral testes with developing sperms, seminal vesicle filled with sperm and male antrum at posterior terminal position. Note also unstained eggs between the testes. b Tyrosinated-tubulin immunoreactivity. Note numerous sensillae of the anterior end, a ring-shaped brain and innervation around the mouth. c Alpha-tubulin immunoreactivity. Prominent ventral neurite

(Fig. 7c). Anterior to the ring, there is an aggregation of sensillae innervated from the brain ring (Fig. 7b). Numerous sensory fibres start from the ventral neurite bundles outwardly, innervating the thick epidermis. Other fibres innervate the ventral side of the body (Fig. 7d).

One of the specimens stained by anti-tyrosinatedtubulin displayed a mouth opening (Fig. 7b). It serves as a focal point for numerous nerve fibres coming from all directions but mainly from the ventral neurite bundles (Fig. 7b).

bundle starting from the ring-shaped brain. Note numerous nerve fibres, going outwards into the epidermal layer. d Alpha-tubulinimmunoreactivity in the posterior end of the animal, showing joining together of the two ventral neurite bundles and the extensive innervation of the ventral side of the animal. Scale bars $50 \mu \mathrm{m} . \mathrm{br}$ brain ring, eg egg, $m$ mouth, $m a$ male antrum, $n f$ nerve fibres, $s$ sensory cells, $s p$ sperms, $s v$ seminal vesicle, $v n$ ventral neurite bundles

In some specimens stained for longer time (about $72 \mathrm{~h}$ ), epidermal glands are revealed and it is possible to follow their innervation (Fig. 8a). Most of them are innervated by nerve fibres coming from the ventral neurite bundles (Fig. 8a). Glands of the anterior end of the body are innervated directly from the brain ring (Fig. 8d). It is possible to follow the nerve fibre making contact with the membrane of the gland cell (Fig. 8b).

The most peculiar glands observed in Nemertoderma cf. are undoubtedly the bottle-shaped ones (Fig. 8c), which are 


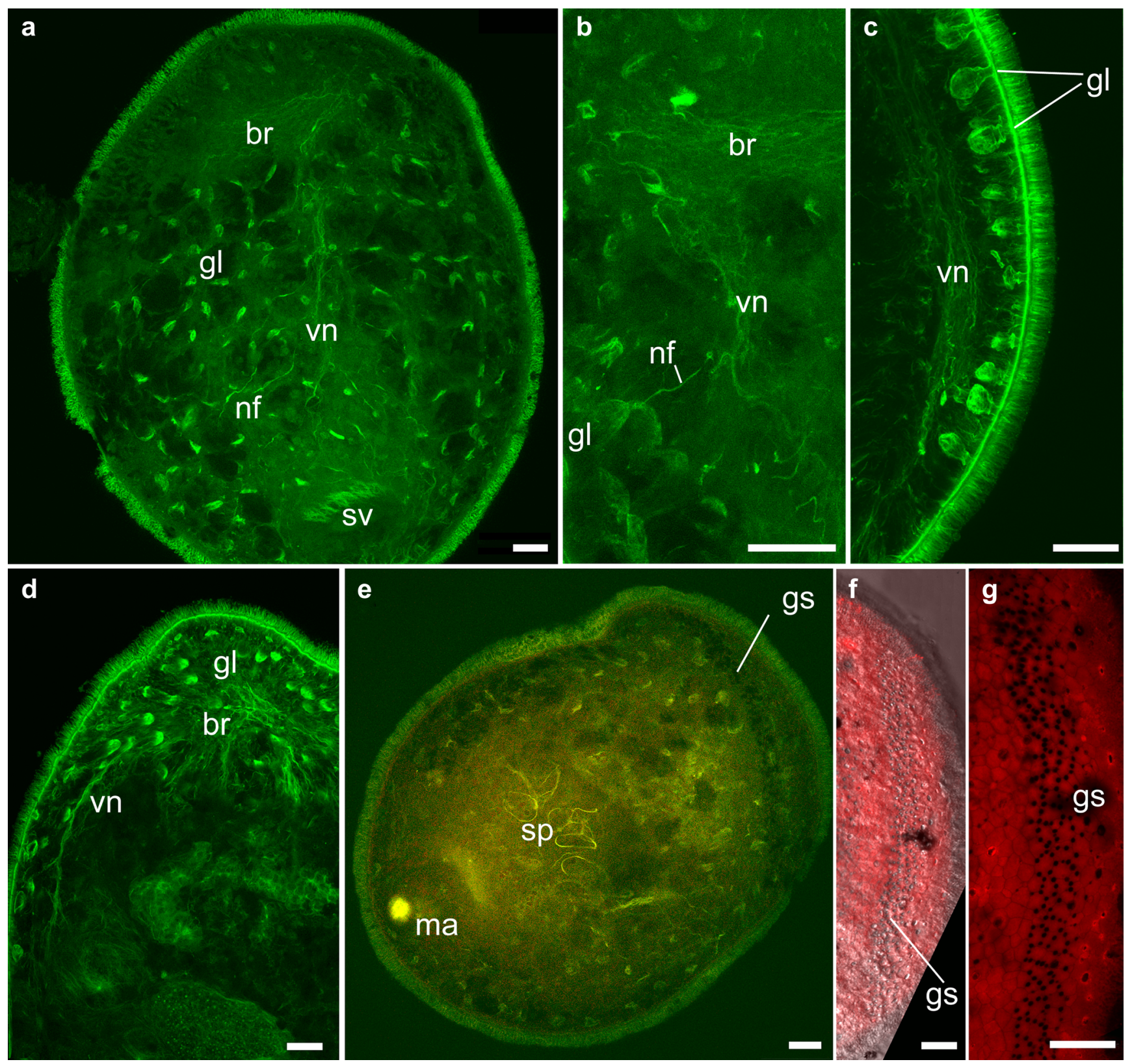

Fig. 8 Confocal laser scanning microscope images of Nemertoderma cf. westbladi. a Alpha-tubulin IR pattern. Overview of an animal at the level of epidermis showing innervation of numerous tubulin IR glands and the seminal vesicle. b Alpha-tubulin IR pattern. Innervation of the gland cells from the brain. $\mathbf{c}$ Tyrosinated-tubulin IR pattern. Innervation of the bottle glands from the ventral longitudinal neurite bundles. d Tyrosinatedtubulin IR pattern. Glands in the anterior part of the body innervated directly from the brain. Note tubulin IR gland openings at the body surface. e Alpha-tubulin IR pattern. Note a stripe of unstained gland neck openings across the anterior end of the body. $f$ Differential contrast image of the stripe of gland neck openings. $\mathrm{g}$ Confocal image of the same stripe. Note gland necks passing between epidermal cells. Scale bars $25 \mu \mathrm{m}$. br brain ring, $g l$ gland, $g s$ glandular stripe, $m a$ male antrum, $n f$ nerve fibres, $s p$ sperms, $v n$ ventral neurite bundles strongly tubulin IR probably due to the lining of microtubules. A row of such glands can be observed along the ventral neurite bundles (Fig. 8c). The presence of bottle glands is characteristic for the family Nemertodermatidae (Sterrer 1998). In small male mature specimens, a distinct stripe of tightly packed gland openings was observed running across the anterior end of the animal (Fig. 8e-g).

\section{Discussion}

\section{Nervous system of nemertodermatids}

Faubel and Dörjes (1978) described the NS of $F$. cf. apelti by traditional histological methods and we can fully confirm the accuracy of this description. Our immunostainings have 
demonstrated that a large number of the neurons are FMRFamide IR, which is true also for the anterior nerve tracts. The 5HT IR cells are fewer, but there are some fibres in the anterior nerve tracts and in the innervation of the broom canal. It is interesting to note that RFamide immunoreactivity seems to dominate in the NS of both $F$. cf. apelti and $N$. cf. westbladi. In the former, the mass of cells anterior to the neuropile are RFamide IR, as are the prominent ventral neurite bundles and the ventral part of the brain ring in the latter (Raikova et al. 2004a).

The brain of Sterreria rubra was described by Faubel (1976) as ring-shaped with dorsal and ventral thickenings in submuscular position and the statocyst embedded in the dorsal part of the brain. Our observations mostly correspond with that of Faubel (1976) and we could also show a subepidermal nerve net composed of mostly FMRFamide and tyrosinated tubulin IR elements. The brain itself is basket-shaped with strong longitudinal neurite bundles and a number of commissures starting right at the anterior end of the body, hence the extensive innervation of this region noted by Faubel (1976). The dorsal thickening of the nerve ring observed by Faubel (1976) contains dorsal, dorso-lateral and lateral neurite bundles, and the statocyst is connected to the dorsal part of the brain. The ventral thickening of the ring, observed by Faubel (1976), contains ventral neurite bundles. The part of the brain encapsulating the statocyst is highly RFamide IR while no 5-HT and little alpha-tubulin immunoreactivity could be detected.

In general, the brain structure of Sterreria spp. resembles a commissural brain as observed in some acoel species, e.g. Childia spp. (Raikova et al. 2004b). The main difference is that in the acoel brain, the commissures are normally of equal thickness or thicker than the longitudinal connectives whereas in Sterreria spp., the connectives are much thicker.

Another description that seems to partly match our observations on Sterreria spp. is Riser's (1987) account of the NS of Nemertinoides elongatus Riser, 1987. Common features are the strong dorso-lateral neurite bundles connected by weaker commissures. However, the large ventral neural mass reported by Riser seems to be a specific feature of $N$. elongatus as we could not detect this in our preparations. Alternatively, the two ventral neurite bundles seen branching into an epidermal nerve net in Fig. 5c may correspond to the "neural mass" described by Riser (1987) from histological sections.

Nervous system anatomy is often regarded as slowevolving or "conserved" and thus particularly useful for reconstructing deep divergences, such as those in early bilaterian evolution (Loesel 2011), a notion that led Harzsch (2002) to coin the term neurophylogeny. In the light of the position of Nemertodermatida as an early branching bilaterian lineage (e.g. Jondelius et al.
2002; Hejnol et al. 2009 and others) or, alternatively as a drastically reduced deuterostome group (Philippe et al. 2011), it is of interest to reconstruct nemertodermatid neuroanatomy in detail as it may help reconstruct the NS of the last common bilaterian ancestor or reveal the features unique to deuterostomes predicted by Philippe et al. (2011).

Brain anatomy appears highly variable within Nemertodermatida. In $F$. cf. apelti, we observed a neuropile, a structure, which was absent from all species of Nemertodermatida previously studied (Raikova et al. 2000a; 2004a). N. westbladi possesses a ring-shaped brain whereas Sterreria spp. have a commissural brain similar to that observed in some species of Acoela (Raikova et al. 2004b). In M. stichopi, there is no anterior centralization, only two thick fibre bundles interconnected in the anterior by weak commissures. The extensive development of what was called the endonal brain by Reisinger (1925) in $F$. cf. apelti can probably be explained by the presence of the broom organ and the necessity to innervate it.

The position of the NS is also variable: in N. westbladi and M. stichopi, it is basiepidermal while it is submuscular in Sterreria spp. and in F. cf. apelti. The earliest bilaterian NS is thought to consist of a diffuse subepidermal nerve net similar to that of cnidarians (Gröger and Schmid 2001). Reisinger (1925) proposed that in the course of evolution nerve elements become more concentrated and the NS sinks below the muscle layers. According to this hypothesis the subepidermal brains of Sterreria spp. and $F$. cf. apelti would be apomorphic and the basiepidermal brain rings of $N$. westbladi would represent the ancestral state. However, plotting the NS characters on a phylogenetic tree based on ribosomal genes and Histone 3 retrieved in a recent molecular phylogenetic study of a taxonomically comprehensive nemertodermatid dataset (Meyer-Wachsmuth and Jondelius 2015) reveals homoplasy in this character (Fig. 9). It is not clear directly from the nemertodermatid phylogeny in Fig. 9 which state is ancestral for Nemertodermatida. Neither is it clear for acoels, as the earliest branching clade, Diopisthoporidae (Jondelius et al. 2011), has a submuscular NS (Westblad 1940; Smith and Tyler 1985; Raikova 2004c), while other basal lineages, such as Hofsteniidae (Steinböck 1966), Solenofilomorphidae (Crezée 1975) and Proporidae (Westblad 1946; Ax, 1963; Faubel 1976), have representatives with a basiepidermal NS, which is suggested to be the ancestral state in Acoela (Westblad 1948, Steinböck 1966, Achatz and Martinez 2012). If indeed the ancestral acoel had a basiepidermal nervous system, this character state can be inferred as the ancestral feature also in Nemertodermatida given monophyly of Acoelomorpha. Under this hypothesis, a submuscular nervous system evolved multiples times independently in Acoela and twice within Nemertodermatida, namely in Flagellophora lineage and Sterreria spp. 


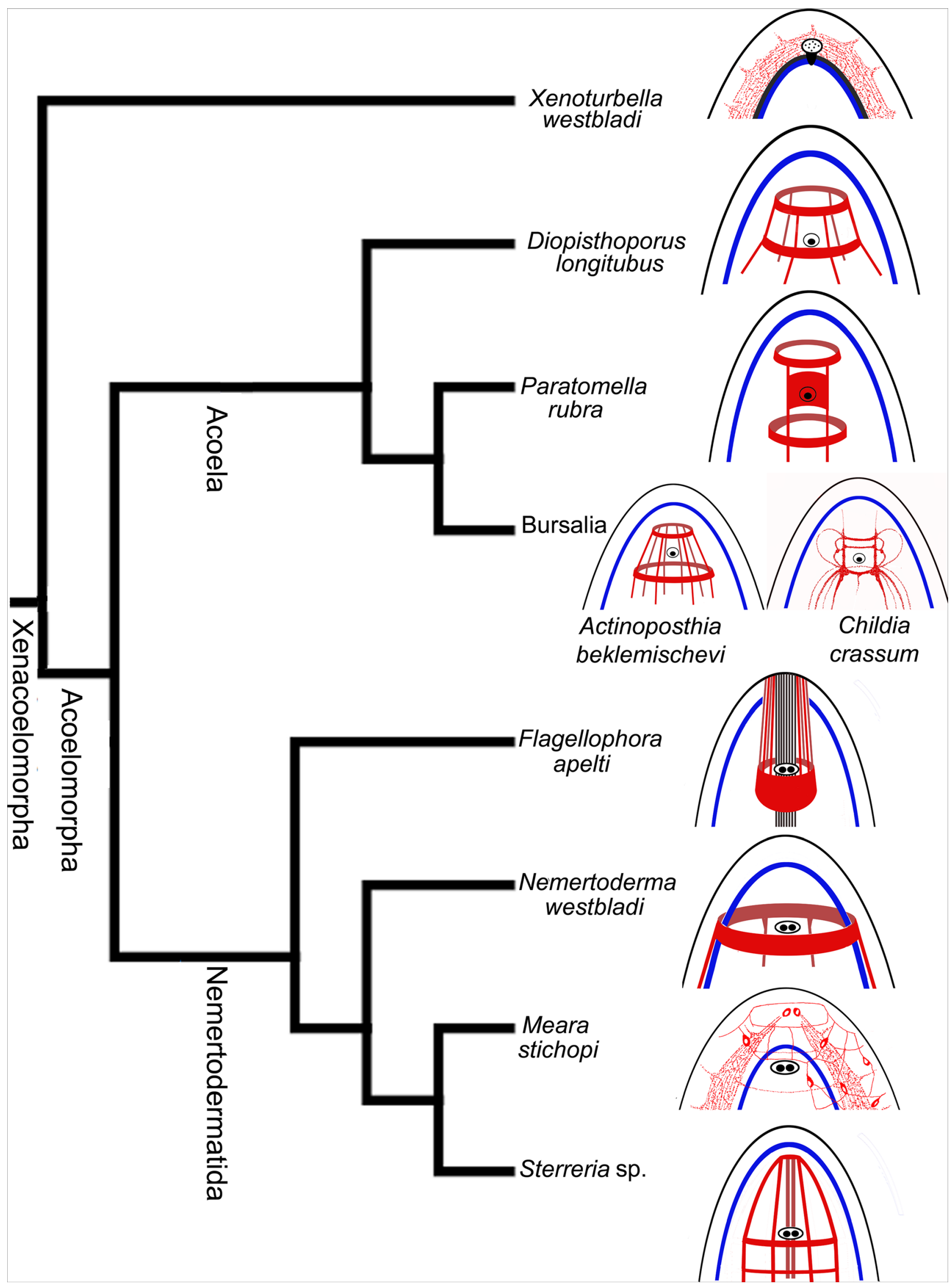


4 Fig. 9 Schematic drawings of the organization of the nervous system $(N S)$ and its position with respect to the body wall musculature $(M)$ of several branches of Xenacoelomorpha; nemertodermatid phylogeny is based on Meyer-Wachsmuth and Jondelius (this issue), that of Acoela on Jondelius et al. (2011). For all species only the anterior part is shown, statocysts and broom organ (Flagellophora) are shown for morphological context. Xenoturbella possesses the hypothesized ancestral basiepidermal nerve net without anterior centralization while in Acoela the nervous system has sunken under the body wall musculature and formed anterior centralisations of different degrees. In Nemertodermatida, the nervous system lies outside the body wall musculature in $N$. westbladi and M. stichopi, two species that are not closely related, and inside the musculature in F. cf. apelti and Sterreria sp. The structure of the nervous system in Nemertodermatida is diverse and does not show a trend from an epidermal nerve net towards an insunk centralized lobed brain. The "primitive" organization of the nervous system in $M$. stichopi could be interpreted as a secondary reduction due to the symbiotic lifestyle of the species. The nervous system is shown in red, the layers of body wall musculature in blue. Figure adapted from Achatz and Martinez (2012). Morphological information based on the following: Xenoturbella westbladi, Raikova et al. 2000b (NS, M); Diopisthoporus longitubus, Raikova 2004c (NS, M); Paratomella rubra, Crezée 1978 (NS, M); Actinoposthia beklemischevi, Raikova et al. 2004c, Raikova et al. 1998 (NS, M); Childia crassum, Reuter et al. 2001a (NS), Raikova et al. 2004b (NS, M); Nemertoderma westbladi, Raikova et al. 2004a (NS, M) and this study (NS); Meara stichopi, Raikova et al. 2000a (NS, M); Flagellophora cf. apelti (NS, M) and Sterreria spp. (NS, M) this study

The ring-like shape of the brain in Nemertoderma and Sterreria is similar to the condition in the two earliest branching acoel clades Diopisthoporus (Westblad, 1940) and Paratomella (Crezée, 1978) indicating that it is most parsimoniously interpreted as the ancestral state for Acoela and under the phylogenetic hypothesis in Fig. 9 ancestral also for Nemertodermatida, i.e. for Acoelomorpha. This condition changed twice within Nemertodermatida: in Flagellophora and in Meara. In the former, the existence of the broom organ may have necessitated changes in brain morphology and the latter is a commensal, which may have led to morphological reductions.

The repeated changes in NS position and morphology within Nemertodermatida demonstrate a large degree of plasticity. The general morphology of the nemertodermatid NS is not at all "conserved"; in comparison with characters such as statocyst morphology and ciliary rootlets, it is evolving rapidly.

Nemertodermatida have been described as having a developed gut with a constantly present lumen at least during some stages of their life (Westblad 1937; Ax 1963; Faubel and Dörjes 1978; Riser 1987). The same is true for the worm Xenoturbella (Westblad 1949a), which is hypothesized to be the sister taxon of Nemertodermatida+Acoela (Hejnol et al. 2009). However, no specific innervation of the gut has been visualized (Raikova et al. 2000a, b). immunoreactivity is known to be widespread in protostome stomatogastric NS, e.g. in Gnathostomulida (Müller and Sterrer 2004), Annelida (Müller and Westheide 2000; 2002) and catenulid and rhabditophoran flatworms (Reuter and Halton 2001; Reuter et al. 2001a; Kotikova et al. 2002), and it is present also in post-metamorphic cnidarians (Grimmelikhuijzen 1983a, 1938b). Both 5-HT- and
FMRFamide immunoreactivity was detected in the gut of tornaria larvae of enteropneusts (Nezlin and Yushin 2004), while it is absent in cnidarian, polyclad and lophotrochozoan larvae (Ruppert 1978; Hay-Schmidt 1995; Dickinson et al. 1999; Hessling 2002; Voronezhskaya et al. 2002; 2003; Wanninger and Haszprunar 2003). The absence of this immunoreactivity in the gut of adult nemertodermatids and Xenoturbella is in accordance with an early bilaterian origin of the lineage rather than a phylogenetic position within Deuterostomia, a group in which a stomatogastric NS is usually present. Secondary loss of gut innervation without loss of the gut itself appears unlikely.

\section{Musculature of nemertodermatids}

Hooge (2001) described the pattern of musculature in S. psammicola specimens from North Carolina as an orthogonal grid with a layer of diagonal musculature lying between the two in the anterior quarter of the body length. He also states that the "two opposing strands of muscles [...] cross each other at right angles", which, however, is not visible in the illustrations (Hooge 2001 Figs. 1a and 2a). Our observations confirm that diagonal fibres are present only in the anterior quarter of the animal. We have been able to visualize for the first time the muscular pattern around the male opening (Fig. 6d). It is curious to note, that the pattern around the male opening is quite similar to that described for the mouth by Hooge (2001) and Todt (2009 figure 9g), with the exception of additional and accessory muscles around the mouth, which we could not see around the male pore.

A simple orthogonal grid of circular and longitudinal muscles without extra muscle layers is believed to be the ancestral pattern of body wall musculature in Bilateria (Schmidt-Rhaesa 2007). Such a pattern has indeed been found in early branching Acoela (Hooge 2001), but not yet in Nemertodermatida. Changes in this pattern have been shown to be phylogenetically informative in Acoela (Hooge 2001; Tyler and Hooge 2004; Jondelius et al. 2011) and may be so also in Nemertodermatida. $N$. westbladi and $M$. stichopi both show complete diagonal musculature while Sterreria spp. has an incomplete layer of diagonal muscles. Given the phylogenetic relationships within Nemertodermatida (Meyer-Wachsmuth and Jondelius 2015), the incompleteness of the diagonal muscle layer in Sterreria spp. can therefore be interpreted as a secondary reduction of the body wall musculature.

\section{Broom organ and other morphological features}

The broom organ had been described at the ultrastructural level only in an abstract without illustrations as a complex of about 30 gland cells with very long necks stiffened by filiform secretion bodies (Tyler 1986). Our immunohistochemical observations seem to be in accordance with this description. The tubulin immunoreactivity observed is likely due to the staining of microtubules that usually line the gland ducts in nemertodermatids 
(Ehlers 1992). The fact that the individual strands of the broom seem to break apart into numerous thinner fibres at the proximal end is also compatible with the idea of microtubules lining the duct. Within the proximal gland cell, where the microtubules originate, they are more serrated than along the gland neck. The observation of granules along the unstained broom strands (Fig. 3h) also speaks in favour of the glandular nature of the broom; these granules probably lie within the gland ducts.

The fact that along the broom, some fibres were stained by phalloidin proves that they contain filamentous actin, thus supporting Faubel and Dörjes' (1978) observation that the "flagellae", the individual strands of the broom, are contractile.

Two functions of the broom organ have been discussed, either as an organ for gathering food in the apparent absence of a mouth (Faubel and Dörjes 1978; Tyler 1986) or as a sensory organ. Since the broom is not flagellar but glandular in nature, the sensory function seems less likely. It is, however, not clear how feeding by the broom organ would work with the now detected mouth.

Epidermal bacteria as observed here in F. cf. apelti have also been described ultrastructurally from M. stichopi (Lundin and Hendelberg 1995) and N. westbladi (Lundin 1998) in which they were considered to be symbiotic. The bacteria described in Lundin (1998) are branching and their thickness varies along their length, while those described here appear straight and even. Furthermore, these bacteria were not detected in all specimens. In $F$. cf. apelti, the observed epidermal bacteria could be explained as infections or parasites but they could also be symbiotic and associated with certain populations only. We are unable to explain the staining of epidermal bacteria by anti-FMRFamide antibodies and their function also remains enigmatic.

\section{Conclusions}

The NS of Nemertodermatida is very variable in terms of position and general morphology. A ring-shaped brain is reconstructed as an ancestral feature of Nemertodermatida, Acoela and Acoelomorpha. The musculature pattern in Sterreria spp. with incomplete diagonal musculature covering only the anterior quarter of the body was reconstructed as secondarily reduced. The complete absence of gut innervation in nemertodermatids is in conflict with the deuterostome hypothesis, but compatible with a position outside Nephrozoa.

amf, anterior muscle fibres; ap, adhesive plate; bc, brain cells; bo, broom organ; boc, broom organ canal; brm, broom retractor muscle; br, brain ring; bs, bursa; bwm, body-wall muscles; cm, circular muscles; dln, dorso-lateral neurite bundles; dm, diagonal musculature; dn, dorsal neurite bundles; dpc, dorsal posterior commissure; eg, egg; ep, epidermis; epb, epidermal bacteria; fgn, frontal gland necks; fp, frontal pore; fsv, false seminal vesicle; g, granules; gl, gland; gs, glandular stripe; ic, innervation of the broom canal; lcy, lithocyte; $1 \mathrm{~m}$, longitudinal muscles; $1 \mathrm{mf}$, lateral muscle fibres; ln, lateral neurite bundles; m, mouth; ma, male antrum; mco, male copulatory organ; mo, male opening; $n$, neuropile; nc, nerve cells; nf, nerve fibres; nn, nerve net; $\mathrm{np}$, neuropile; $\mathrm{pc}$, penis cone; prm, parenchymal retractor muscle; rh, rhabdoids; s, sensory cells; sp, sperms; sph, sphincter; st, statocyst; stf, statocyst nerve fibres; stl, statolith; sv, seminal vesicle; tc, transversal commissure; U, U-shaped muscles; vn, ventral neurite bundles

Acknowledgments Thanks are extended to the staff of Sven Lovén Centre for Marine Sciences (Sweden), the CCMAR in Faro (Portugal) and the Biologische Anstalt Helgoland (Germany) for their help with collecting the material. We are deeply grateful to Professor Marco Curini-Galletti, to Professor Mark Martindale and to Professor Philippe Bouchet for organizing sampling in Italy, at Hawai'i and in Papua New Guinea, respectively. Collections in Papua New Guinea took place during the Our Planet Reviewed Papua Niugini Expedition in November-December 2012, organized by the Muséum National d'Histoire Naturelle (MNHN), Pro Natura International, the Institut de Recherche pour le Développement (IRD) and the University of Papua New Guinea. The principal investigators of this expedition were Philippe Bouchet, Sarah Samadi (MNHN) and Claude Payri (IRD), and funding was provided by the Total Foundation, Prince Albert II of Monaco Foundation, Fondation EDF, Stavros Niarchos Foundation and Entrepose Contracting, with support from the Divine Word University and operated under a permit delivered by the Papua New Guinea Department of Environment and Conservation. The confocal microscopic observations were carried out at the newly equipped Research Resource Centre "Molecular and Cellular Technologies" at St.-Petersburg State University (Russia). We wish to express our gratitude to the most helpful staff of the Centre, in particular to Nikolai A. Kostin, specialist in confocal microscopy. Financial support was received from the Zoological Institute RAS project 0120135194 and the Russian Basic Research Foundation grant 13-04-02002 to Olga Raikova, the Swedish Research Council through a grant to Ulf Jondelius (grant numbers 2009-5147 and 2012-3913), the Föreningen Riksmusei Vänner (stipend 2011), Stiftelsen Lars Hiertas Minne grant FO2011-0248 and the Royal Swedish Academy of Sciences grant FOA11H-352 to Inga Meyer-Wachsmuth, and from the European Community through an ASSEMBLE grant (agreement no 227799).

\section{References}

Achatz, J. G., \& Martinez, P. (2012). The nervous system of Isodiametra pulchra (Acoela) with a discussion on the neuroanatomy of the Xenacoelomorpha and its evolutionary implications. Frontiers in Zoology, 9, 27-48.

Ax, P. (1963). Relationships and phylogeny of the Turbellaria. In E. C. Dougherty (Ed.), The Lower Metazoa (pp. 191-224). Berkeley, California: University California Press.

Børve, A., \& Hejnol, A. (2014). Development and juvenile anatomy of the nemertodermatid Meara stichopi (Bock) Westblad 1949 (Acoelomorpha). Frontiers in Zoology, 11, 50-64.

Coons, A. H., Leduc, E. H., \& Conolly, J. M. (1955). Studies on antibody production I. A method for the histochemical demonstration of specific antibody and its application to a study of the hyperimmune rabbit. Journal of Experimental Medicine, 102, 49-60.

Crezée, M. (1975). Monograph of the Solenofilomorphidae (Turbellaria: Acoela). Internationale Revue der gesamten Hydrobiologie und Hydrographie, 60, 769-845. 
Crezée, M. (1978). Paratomella rubra Rieger and Ott, an amphiatlantic acoel turbellarian. Cahiers de Biologie Marine, 19, 1-9.

Dickinson, A. J. G., Nason, J., \& Croll, R. P. (1999). Histochemical localization of FMRFamide, serotonin and catecholamines in embryonic Crepidula fornicata (Gastropoda, Prosobranchia). Zoomorphology, 119, 49-62.

Ehlers, U. (1985). Das Phylogenetische System der Plathelminthes. Stuttgart: G. Fischer.

Ehlers, U. (1992). Frontal glandular and sensory structures in Nemertoderma (Nemertodermatida) and Paratomella (Acoela): ultrastructure and phylogenetic implications for the monophyly of the Euplathelminthes (Plathelminthes). Zoomorphology, 112, 227-236.

Faubel, A. (1976). Interstitielle Acoela (Turbellaria) aus dem Litoral der nordfriesischen Inseln Sylt und Amrum (Nordsee). Mitteilungen aus dem Hamburgischen Zoologischen Museum und Institut, 73, 17-56.

Faubel, A., \& Dörjes, J. (1978). Flagellophora apelti gen. n. sp. n.: a remarkable representative of the order Nemertodermatida (Turbellaria: Archoophora). Senckenbergiana maritima, 10, 1-13.

Grimmelikhuijzen, C. J. P. (1983a). Coexistence of neuropeptides in Hydra. Neuroscience, 9(4), 837-845

Grimmelikhuijzen, C. J. P. (1983b). FMRFamide immunoreactivity is generally occurring in the nervous systems of coelenterates. Histochemistry, 78(3), 361-81.

Gröger, H., \& Schmid, V. (2001). Larval development in Cnidaria: a connection to bilateria? Genesis, 29, 110-114.

Harzsch, S. (2002). Neurobiologie und Evolutionsforschung: "Neurophylogenie" und die stammesgeschichte der Euarthropoda. Neuroforum, 4(2), 267-273.

Hay-Schmidt, A. (1995). The larval nervous system of Polygordius lacteus Scheinder 1868 (Polygordiidae, Polychaeta): immunocytochemical data. Acta Zoologica, 76, 121-140.

Hejnol, A., Obst, M., Stamatakis, A., et al. (2009). Assessing the root of bilaterian animals with scalable phylogenomic methods. Proceedings of the Royal Society B, 276, 4261-4270.

Hessling, R. (2002). Metameric organization of the nervous system in developmental stages of Urechis caupo (Echiura) and its phylogenetic implications. Zoomorphology, 121, 221-234.

Hooge, M. D. (2001). Evolution of the body wall musculature in the Platyhelminthes (Acoelomorpha, Catenulida, Rhabditophora). Journal of Morphology, 249, 171-194.

Jondelius, U., Ruiz-Trillo, I., Baguñà, J., \& Ruitort, M. (2002). The Nemertodermatida are basal bilaterians and not members of the Platyhelminthes. Zoologica Scripta, 31, 201-215.

Jondelius, U., Wallberg, A., Hooge, M., \& Raikova, O. I. (2011). How the worm got its pharynx: phylogeny, classification and Bayesian assessment of character evolution in Acoela. Systematic Biology, 60, $845-871$

Karling, T. G. (1940). Zur Morphologie und Systematik der Alloeocoela Cumulata and Rhabditophora Lecithophora (Turbellaria). Acta Zoologica Fennica, 26, 1-160.

Kotikova, E. A., Raikova, O. I., Reuter, M., \& Gustafsson, M. K. S. (2002). The nervous and muscular systems in the free-living flatworm Castrella truncata (Rhabdocoela): an immunocytochemical and phalloidin fluorescence study. Tissue and Cell, 34, 365-374.

Leiper, R. T. (1902). On an acoelous turbellarian inhabiting the common heart urchin. Nature, 66, 641.

Loesel, R. (2011). Chapter 11: Neurophylogeny: retracing early metazoan brain evolution. In P. Pontarotti (Ed.), Evolutionary biology-concepts, biodiversity, macroevolution and genome evolution (pp. 169191). Berlin Heidelberg: Springer.

Lundin, K. (1998). Symbiotic bacteria on the epidermis of species of the Nemertodermatida (Platyhelminthes, Acoelomorpha). Acta Zoologica, 79, 187-191
Lundin, K. (2000). Phylogeny of the Nemertodermatida (Acoelomorpha, Platyhelminthes). A cladistic analysis. Zoologica Scripta, 29, 65-74.

Lundin, K., \& Hendelberg, J. (1995). Ultrastructure of the epidermis of Meara stichopi (Platyhelminthes, Nemertodermatida) and associated extra-epidermal bacteria. Hydrobiologia, 305, 161-165.

Meyer-Wachsmuth, I., Raikova, O. I., \& Jondelius, U. (2013). The muscular system of Nemertoderma westbladi and Meara stichopi (Nemertodermatida, Acoelomorpha). Zoomorphology, 132, 239-252.

Meyer-Wachsmuth, I., Curini Galletti, M., \& Jondelius, U. (2014). Hyper-cryptic marine meiofauna: species complexes in Nemertodermatida. PLOS One, 9(9), 1-25.

Meyer-Wachsmuth, I., Jondelius, U. (2015). Interrelationships of Nemertodermatida. Organisms Diversity and Evolution, this issue.

Müller, M. C. M., \& Sterrer, W. (2004). Musculature and nervous system of Gnathostomula peregrina (Gnathostomulida) shown by phalloidin labelling, immunohistochemistry, and cLSM, and their phylogenetic significance. Zoomorphology, 123, 169-177.

Müller, M. C. M., \& Westheide, W. (2000). Structure of the nervous system of Myzostoma cirriferum (Annelida) as revealed by immunohistochemistry and cLSM analyses. Journal of Morphology, 245, 87-98.

Müller, M. C. M., \& Westheide, W. (2002). Comparative analysis of the nervous systems in presumptive progenetic dinophilid and dorvilleid polychaetes (Annelida) by immunohistochemistry and cLSM. Acta Zoologica, 83, 33-48.

Nezlin, L. P., \& Yushin, V. V. (2004). Structure of the nervous system in the tornaria larva of Balanoglossus proterogonius (Hemichordata: Enteropneusta) and its phylogenetic implications. Zoomorphology, $123,1-13$.

Paps, J., Baguña, J., \& Riutort, M. (2009). Bilaterian phylogeny: a broad sampling of 13 nuclear genes provides a new Lophotrochozoa phylogeny and supports a paraphyletic basal Acoelomorpha. Molecular Biology and Evolution, 26(10), 2397-2406.

Perea-Atienza, E., GavilaÏn, B., Chiodin, M., Abril, J. F., Hoff, K. J., Poustk, A. J., \& Martinez, P. (2015). The nervous system of Xenacoelomorpha: a genomic perspective. Journal of Experimental Biology, 218, 618-628.

Philippe, H., Brinkmann, H., Copley, R. R., et al. (2011). Acoelomorph flatworms are deuterostomes related to Xenoturbella. Nature, 470, $255-258$.

Raikova, O. I., Reuter, M., Kotikova, E. A., \& Gustafsson, M. K. S. (1998). A commissural brain! The pattern of 5-HT immunoreactivity in Acoela (Plathelminthes). Zoomorphology, 118, 69-77.

Raikova, O. I., Reuter, M., Jondelius, U., Gustafsson, M. K. S. (2000a). The brain of Nemertodermatida as revealed by anti-5-HT and antiFMRFamide immunostainings. Tissue and Cell, 32, 358-365.

Raikova, O.I., Reuter, M., Jondelius, U., Gustafsson, M. K. S. (2000b). An immunocytochemical and ultrastructural study of the nervous and muscular systems of Xenoturbella westbladi (Bilateria inc. sed). Zoomorphology, 120, 107-118.

Raikova, O. I., Reuter, M., Gustafsson, M. K. S., Maule, A. G., Halton, D. W., Jondelius, U. (2004a). Basiepidermal nervous system in Nemertoderma westbladi (Nemertodermatida): GYIRFamide immunoreactivity. Zoology, 107, 75-86.

Raikova, O. I., Reuter, M., Gustafsson, M. K. S., Maule, A. G., Halton, D. W. (2004b). Evolution of the nervous system in Paraphanostoma (Acoela). Zoologica Scripta, 33, 71-88.

Raikova, O. I. (2004c). Neuroanatomy of basal bilaterians (Xenoturbellida, Nemertodermatida, Acoela) and its phylogenetic implications ( $\mathrm{PhD}$ thesis). Åbo, Finland: Åbo Akademi University.

Reisinger, E. (1925). Untersuchungen am Nervensystem der Bothrioplana semperi Braun. (Zugleich ein Beitrag zur Technik 
der vitalen Nervenfaerbung und zur vergleichenden Anatomie des Plathelminthennervensystems.). Zeitschrift für Morphologie und Ökologie der Tiere, 5, 119-149.

Richter, S., Loesel, R., Purschke, G., Schmidt-Rhaesa, A., et al. (2010). Invertebrate neurophylogeny: suggested terms and definitions for a neuroanatomical glossary. Frontiers in Zoology, 7, 29.

Reuter, M., \& Halton, D. W. (2001). Comparative neurobiology of Platyhelminthes. In D. T. J. Littlewood \& R. A. Bray (Eds.), Interrelationships of the Platyhelminthes (pp. 239-249). London: Taylor \& Francis.

Reuter, M., Raikova, O. I., Gustafsson, M. K. S. (2001a). Patterns in the nervous and muscle systems in lower flatworms. Belgian Journal of Zoology, 31, 47-53.

Reuter, M., Raikova O. I., Jondelius, U., Gustafsson, M. K. S., Maule A. G., Halton, D. W. (2001b). Organisation of the nervous system in the Acoela: an immunocytochemical study. Tissue and Cell, 33(2), 119-128.

Riser, N. W. (1987). Nemertinoides elongatus gen. n., sp. n. (Turbellaria: Nemertodermatida) from coarse sand beaches of the western north Atlantic. Proceedings of the Helminthological Society of Washington, 54, 60-67.

Ruppert, E. E. (1978). A review of metamorphosis of turbellarian larvae. In F.-S. Chia \& M. E. Rice (Eds.), Settlement and metamorphosis of marine invertebrate larvae (pp. 65-81). New York: Elsevier.

Schmidt-Rhaesa, A. (2007). The evolution of organ systems. Oxford, New York: Oxford University Press.

Smith, J. P. S., \& Tyler, S. (1985). The acoel turbellarians: kingpins of metazoan evolution or a specialized offshoot? In C. Conway-Morris, J. D. George, R. Gibson, \& H. M. Platt (Eds.), The origins and relationships of lower invertebrates (pp. 123-142). Oxford University Press: Oxford.

Srivastava, M., Mazza-Curll, K. L., van Wolfswinkel, J. C., \& Reddien, P. W. (2014). Whole-body acoel regeneration is controlled by Wnt and Bmp-Admp signaling. Current Biology, 24, 1107-1113.

Steinböck, O. (1930). Ergebnisse einer von E. Reisinger \& O. Steinböck mit Hilfe des Rask-Ørsted Fonds durchgeführten Reise in Grönland 1926. 2. Nemertoderma bathycola nov. gen. nov. spec. Videnskabelige Meddelelser Dansk Naturhistorisk Forening, 90, 47-84.

Steinböck, O. (1932). Die Turbellarian des arktischen Gebietes. In F. Römer \& F. Schaudinn (Eds.), Fauna Arctica (Band 6 (pp. 297 342). Jena: Gustav Fischer.

Steinböck, O. (1938). Über die Stellung der Gattung Nemertoderma Steinböck im System der Turbellarien. Acta Societatis pro Fauna et Flora Fennica, 62, 1-28.

Steinböck, O. (1966). Die Hofsteniiden (Turbellaria acoela): Grundsättzliches zur Evolution der Turbellarien. Zeitschrift für zoologische Systematik und Evolutionsforschung, 4, 58-195.
Stefanini, M., De Martino, C., \& Zamboni, L. (1967). Fixation of ejaculated spermatozoa for electron microscopy. Nature, 216, 172-174.

Sterrer, W. (1970). In R. Riedl (Ed.), Fauna und Flora der Adria. Ein systematischer Meeresführer für Biologen und Naturfreunde. Hamburg, Berlin: Verlag Paul Parey.

Sterrer, W. (1998). New and known Nemertodermatida (PlatyhelminthesAcoelomorpha) - a revision. Belgian Journal of Zoology, 128, $55-92$.

Todt, C. (2009). Structure and evolution of the pharynx simplex in acoel flatworms (Acoela). Journal of Morphology, 270, 271-290.

Tyler, S. (1986). Ultrastructure of a remarkable food-gathering organ in Flagellophora sp. (Turbellaria, Nemertodermatida). Transactions of the American Microscopical Society, 105, $90 \mathrm{~A}$.

Tyler, S., \& Hooge, M. (2004). Comparative morphology of the body wall in flatworms (Platyhelminthes). Canadian Journal of Zoology, $82,194-210$

Voronezhskaya, E. E., Tyurin, S. A., \& Nezlin, L. P. (2002). Neuronal development in larval chiton Ischnochiton hakodadensis (Mollusca: Polyplacophora). Journal of Comparative Neurolology, 444, 25-38.

Voronezhskaya, E. E., Tsitrin, E. B., \& Nezlin, L. P. (2003). Neuronal development in the larval polychaete Phyllodoce maculata (Phyllodocidae). Journal of Comparative Neurolology, 455, 299-309.

Wallberg, A., Curini-Galetti, M., Ahmadzadeh, A., \& Jondelius, U. (2007). Dismissal of Acoelomorpha: Acoela and Nemertodermatida are separate early bilaterian clades. Zoologica Scripta, 36, 509-523.

Wanninger, A., \& Haszprunar, G. (2003). The development of the serotonergic and FMRF-amidergic nervous system in Antalis entalis (Mollusca, Scaphopoda). Zoomorphology, 122, 77-85.

Westblad, E. (1937). Die Turbellarien-Gattung Nemertoderma Steinböck. Acta Societatis pro Fauna et Flora Fennica, 60, 45-89.

Westblad, E. (1940). Studien über skandinavische Turbellaria Acoela I. Arkiv för Zoologi, 32A(20), 1-82.

Westblad, E. (1945). Studien über skandinavische Turbellaria Acoela III. Arkiv för Zoologi, 36A(5), 1-56.

Westblad, E. (1946). Studien über skandinavische Turbellaria Acoela IV. Arkiv för Zoologi, 38A(1), 1-56.

Westblad, E. (1948). Studien über skandinavische Turbellaria Acoela V. Arkiv för Zoologi, 41(7), 1-83.

Westblad, E. (1949a). Xenoturbella bocki n.g., n.sp., a peculiar, primitive turbellarian type. Arkiv för Zoologi, 1, 3-29.

Westblad, E. (1949b). On Meara stichopi (Bock) Westblad, a new representative of Turbellaria Archoophora. Arkiv för Zoologi, 1(5), 43-57. 